\title{
Neogenin neutralization prevents photoreceptor loss in inherited retinal degeneration
}

\author{
Jason Charish, ${ }^{1,2}$ Alireza P. Shabanzadeh, ${ }^{1,3}$ Danian Chen, ${ }^{4,5,6}$ Patrick Mehlen, ${ }^{7}$ Santhosh Sethuramanujam, ${ }^{8}$ Hidekiyo Harada, ${ }^{1}$ \\ Vera L. Bonilha, ${ }^{9}$ Gautam Awatramani, ${ }^{8}$ Rod Bremner, ${ }^{4,10,11}$ and Philippe P. Monnier ${ }^{1,2,11}$ \\ 'Vision Division, Krembil Research Institute, Toronto, Ontario, Canada. ²Department of Physiology and ${ }^{3}$ Department of Anatomy, Faculty of Medicine, University of Toronto, Toronto, Ontario, Canada. \\ ${ }^{4}$ Lunenfeld-Tanenbaum Research Institute, Mount Sinai Hospital, Toronto, Ontario, Canada. ${ }^{5}$ Research Laboratory of Ophthalmology and Vision Sciences, State Key Laboratory of Biotherapy and \\ ${ }^{6}$ Department of Ophthalmology, West China Hospital, Sichuan University, Chengdu, China. ${ }^{~}$ Apoptosis, Cancer and Development Laboratory, INSERM U1052, CNRS UMR5286, Université de Lyon, Lyon, \\ France. ${ }^{8}$ Department of Biology, University of Victoria, Victoria, British Columbia, Canada. ${ }^{9}$ Cole Eye Institute, Cleveland Clinic, Cleveland, Ohio, USA. ${ }^{10}$ Department of Laboratory Medicine and Pathobiology \\ and "Department of Ophthalmology and Vision Science, Faculty of Medicine, University of Toronto, Toronto, Ontario, Canada.
}

\begin{abstract}
Inherited retinal degenerations (IRDs) are characterized by the progressive loss of photoreceptors and represent one of the most prevalent causes of blindness among working-age populations. Cyclic nucleotide dysregulation is a common pathological feature linked to numerous forms of IRD, yet the precise mechanisms through which this contributes to photoreceptor death remain elusive. Here we demonstrate that cAMP induced upregulation of the dependence receptor neogenin in the retina. Neogenin levels were also elevated in both human and murine degenerating photoreceptors. We found that overexpressing neogenin in mouse photoreceptors was sufficient to induce cell death, whereas silencing neogenin in degenerating murine photoreceptors promoted survival, thus identifying a pro-death signal in IRDs. A possible treatment strategy is modeled whereby peptide neutralization of neogenin in Rd1, Rd10, and Rho P23H-knockin mice promotes rod and cone survival and rescues visual function as measured by light-evoked retinal ganglion cell recordings, scotopic/photopic electroretinogram recordings, and visual acuity tests. These results expose neogenin as a critical link between cAMP and photoreceptor death, and identify a druggable target for the treatment of retinal degeneration.
\end{abstract}

\section{Introduction}

In industrialized countries, a major cause of blindness is the progressive death and dysfunction of photoreceptors (1), most commonly due to age-related macular degeneration (AMD) and inherited retinal degenerations (IRDs). IRDs represent a broad spectrum of disorders that are characterized by the progressive loss of photoreceptor cells, eventually leading to visual impairment or blindness. The most common IRD subtype is retinitis pigmentosa (RP), which involves mutation-dependent progressive loss of rod photoreceptors. RP is almost always monogenetic in origin and can exist in syndromic and nonsyndromic forms, with more than 65 disease-causing genes (2) and nearly 3100 mutations within these genes having been identified (3). Ultimately the mutations result in the disruption of some aspect of the normal structure, function, or metabolism of photoreceptors or the retinal pigment epithelium (RPE). Regardless of the specific gene mutated, the outcome is the progressive death of rod photoreceptors, followed by secondary loss of cones; this irreversible and progressive photoreceptor loss is the major determinant of permanent functional deficits, with reduction in thickness of the photoreceptor-containing outer nuclear layer (ONL) correlating closely with the decline in visual

Conflict of interest: The authors have declared that no conflict of interest exists. Copyright: (c) 2020, American Society for Clinical Investigation.

Submitted: October 30, 2018; Accepted: January 14, 2020; Published: March 16, 2020.

Reference information: J Clin Invest. 2020;130(4):2054-2068.

https://doi.org/10.1172/JCI125898. function (4). Despite the genetic heterogeneity associated with IRDs, common downstream pathways may ultimately promote photoreceptor death (5). Thus, identifying a druggable convergent pro-death trigger in photoreceptors would help generate a therapeutic approach relevant to numerous types of IRD.

Tightly regulated photoreceptor cyclic nucleotide levels are key for normal photoreceptor functioning, and the dysregulation of cyclic nucleotide signaling has garnered interest as a common pathophysiological feature characterizing degenerating photoreceptors $(6,7)$. Moreover, cyclic nucleotide signaling influences pathways that promote context-dependent cell survival or death (8). cGMP levels in photoreceptors vary due to their central role in phototransduction; upon light stimulation, there is a phosphodiesterase-mediated (PDE-mediated) decrease in intracellular cGMP levels leading to hyperpolarization of the cell. cAMP levels in photoreceptors also vary in a dynamic fashion, with light-induced suppression during daytime and elevated cAMP at night, as regulated by a feedback loop involving dopamine, cAMP, and melatonin (9). cAMP in turn plays roles in photoreceptor phenomena including light adaptation (9-11), outer segment membrane renewal, and disc shedding (12). Elevated levels of retinal cGMP (13) or cAMP (1416) have been observed in various animal IRD models and have been posited as a common contributor to photoreceptor death $(8,17)$. The mechanisms by which cyclic nucleotides promote photoreceptor death are unclear, though they may involve PKAor PKG-mediated alterations in protein expression (18). 
A
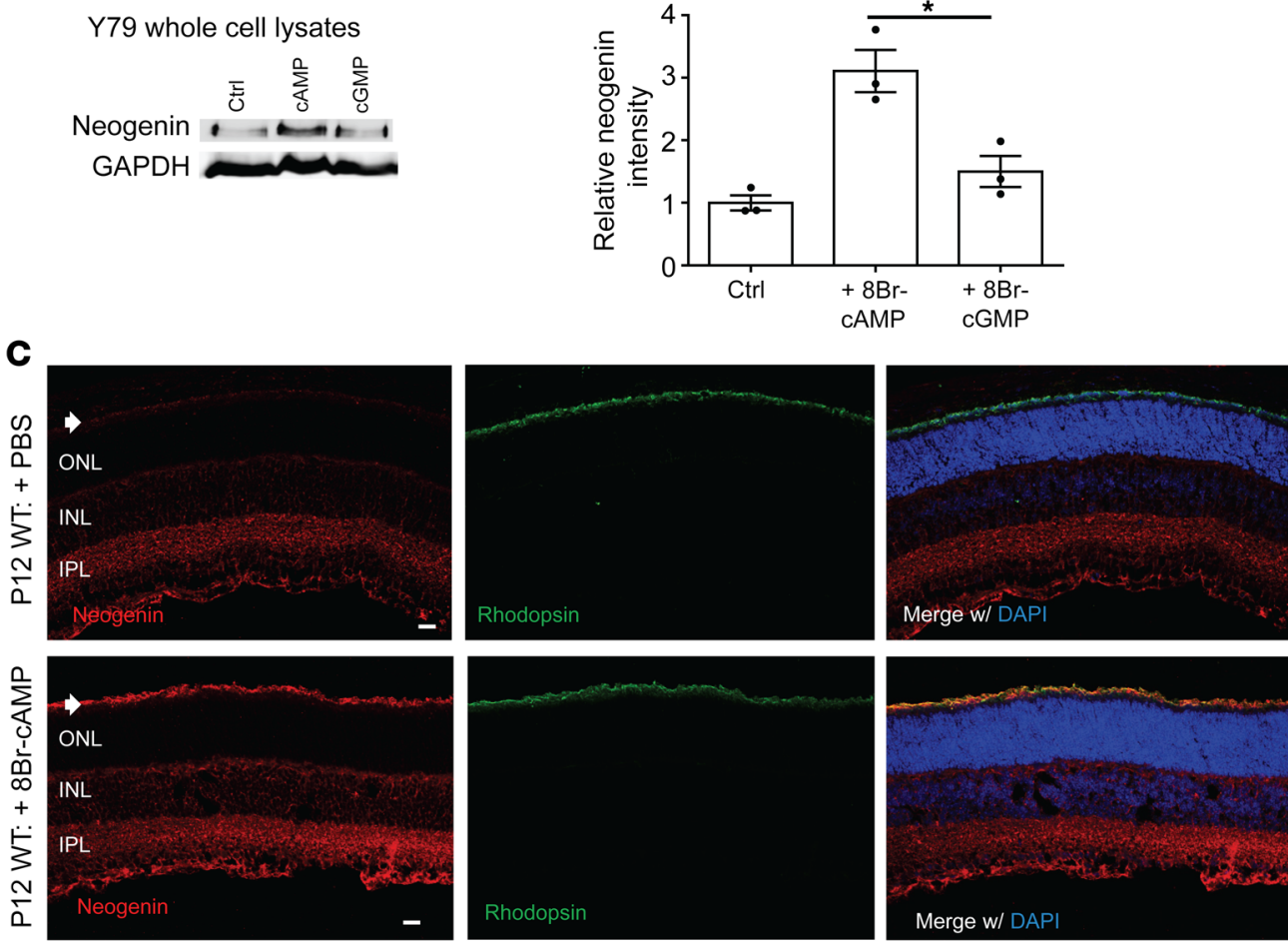

D
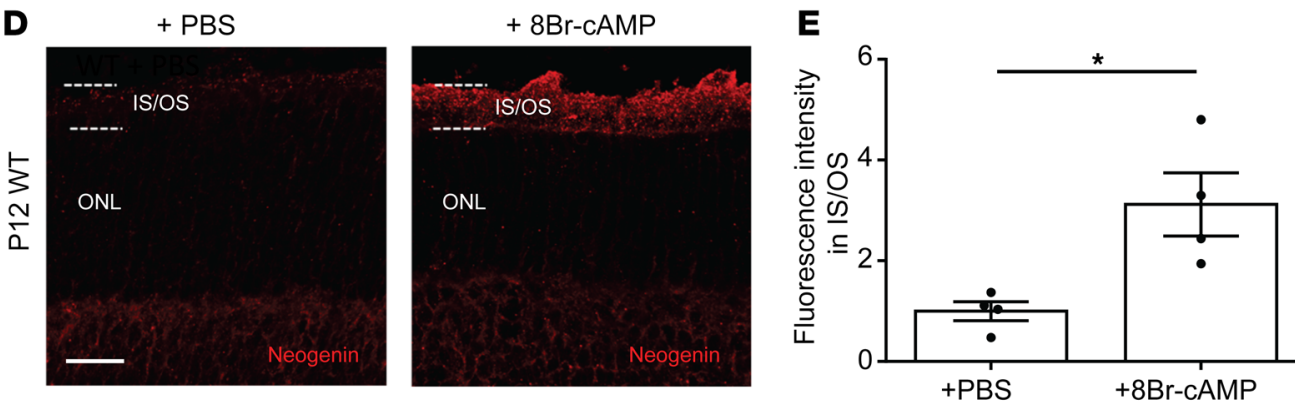

Figure 1. cAMP induces neogenin expression in the retina. (A and B) Retinoblastoma (Y79) cells were cultured with or without 0.5 mM 8-Br-cAMP (cAMP) or $0.5 \mathrm{mM}$ 8-Br-cGMP (cGMP) for 48 hours.

(A) Western blot of neogenin from Y79 whole cell lysates following the indicated treatment. Ctrl, Control. (B) Quantification of data from A, normalized to GAPDH ( $n=3$ for each; $\left.{ }^{*} P<0.05,{ }^{*} P<0.01\right)$. Significance determined by 1-way ANOVA followed by Šidák's multiple-comparisons test. (C-E) P9 [57BL/6] (WT) mice received 1 intravitreal injection of either 10 $\mathrm{mM} 8 \mathrm{Br}$-cAMP or PBS. Eyes were harvested on P12 and cryosectioned. (C) Representative images of $\mathrm{P} 12$ retina treated with PBS or $10 \mathrm{mM} 8 \mathrm{Br}$-CAMP and stained for neogenin (red), rhodopsin (green), and nuclei (DAPI; blue). Arrows indicate inner/outer segments of photoreceptors. IPL, inner plexiform layer. Scale bars: 20 $\mu \mathrm{m}$. (D) Higher-magnification images of $\mathrm{P} 12$ retina treated with $\mathrm{PBS}$ or $8 \mathrm{Br}$-cAMP stained for neogenin (red), with the dashed lines indicating the border of the inner/outer segments (IS/OS). Note the characteristic punctate appearance of neogenin staining. Scale bar: $20 \mu \mathrm{m}$. (E) Quantification of data from $\mathbf{D}$. Neogenin signal in the IS/OS was significantly elevated following $8 \mathrm{Br}$-CAMP intravitreal injection ( $n=4$ for each; $\left.{ }^{*} P<0.05\right)$. Significance determined by Student's $t$ test.
cAMP regulates the expression of transmembrane proteins (19); therefore, we wondered whether it may also influence expression of the cell surface receptor neogenin, which is a key player in multiple cellular events occurring in both the injured CNS and in eye diseases (20). Neogenin is a "dependence receptor" in neurons, which means that when bound to its ligand RGMa, it maintains cell survival, whereas the unbound state promotes cell death (21). Neogenin acts as a major trigger of cell death in several models of retinal pathology (22); thus, we asked whether it also influences photoreceptor survival.

Here, we demonstrate that cAMP promotes photoreceptor death through a neogenin-dependent mechanism. We show elevated neogenin protein levels in multiple animal models of RP, as well as retinas from donors with retinal degeneration. Overexpressing neogenin in mouse photoreceptors was sufficient to promote cell death, whereas silencing neogenin promoted survival in degenerating photoreceptors. Peptide neutralization of neogenin in animal models of $\mathrm{RP}$ in turn rescued light-evoked retinal ganglion cell (RGC) responses, preserved scotopic and photopic electroretinogram responses, and improved visual acuity. These results support the notion that targeting neogenin represents a druggable approach to prevent photoreceptor death and loss of vision in retinal degenerative diseases.

\section{Results}

cAMP induces neogenin-mediated photoreceptor death. In order to test the hypothesis that cAMP or cGMP may affect neogenin levels, we first used a human retinoblastoma cell line (Y79). These cells were chosen because they express photoreceptor genes such as rhodopsin and rod cGMP PDE6 (23); however, they are limited by the fact that they derive from retinoblastoma and do not necessarily behave like photoreceptors. We cultured these cells in the presence or absence of a cell-permeable cGMP analog $(0.5 \mathrm{mM}$ 8Br-cGMP) or a cell-permeable cAMP analog (0.5 mM 8Br-cAMP) for 48 hours. $8 \mathrm{Br}$-cAMP, but not $8 \mathrm{Br}-\mathrm{cGMP}$, resulted in an approximately 3 -fold increase in neogenin protein levels (Figure 1 , A and B). A similar induction of neogenin expression was observed in dissociated cultures of murine rod photoreceptors when treated with $1 \mathrm{mM} 8 \mathrm{Br}$-cAMP for 24 hours (Supplemental Figure 1A; supplemental material available online with this article; https://doi. org/10.1172/JCI125898DS1). 
A

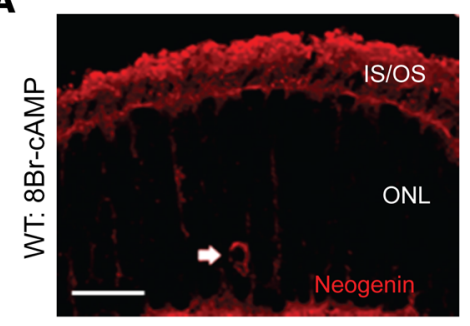

C

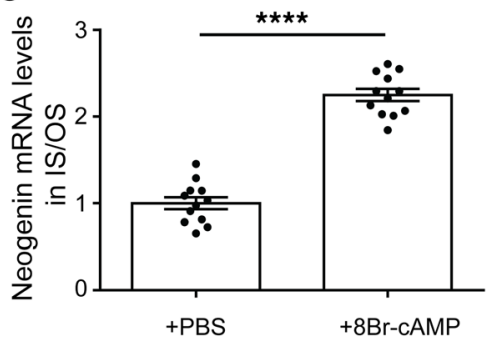

$\mathbf{E}$

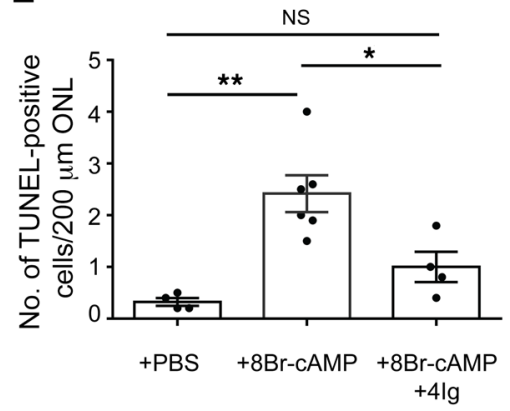

B
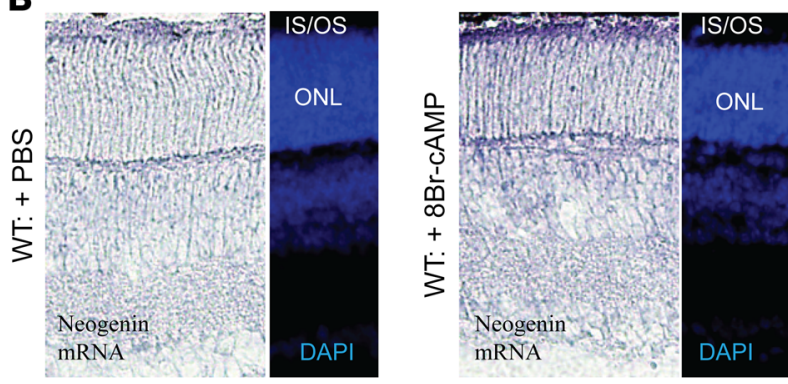

D
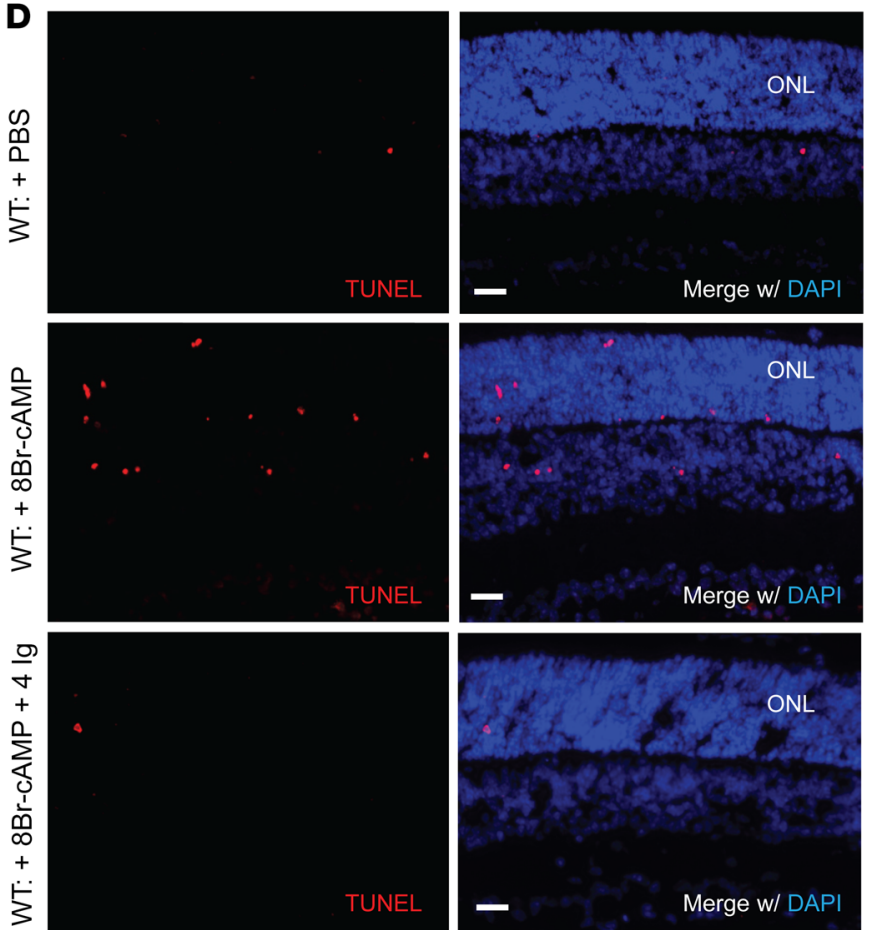

Figure 2. cAMP promotes photoreceptor cell death through neogenin. (A) P9 C57BL/6] (WT) mice received an intravitreal injection of $10 \mathrm{mM} 8 \mathrm{Br}$ - $\mathrm{CAMP}$, and eyes were harvested on P12. Intravitreal injection of 8Br-cAMP led to accumulation of neogenin in the soma of some photoreceptors (arrow), possibly related to initiation of cell death. Note: Gain settings were increased for this image. Scale bar: $20 \mu \mathrm{m}$. (B and C) P9 C57BL/6) (WT) mice received an intra vitreal injection of $10 \mathrm{mM} 8 \mathrm{Br}$-cAMP, and eyes were harvested on P11. In situ hybridization was performed to assess neogenin mRNA levels. (C) Quantification of data from B. 8Br-CAMP led to a significant increase in neogenin mRNA levels in the IS/OS. $n=12$ for each; ${ }^{* * * *} P<0.0001$. Significance determined using Student's $t$ test. (D and E) P9 WT mice received an intravitreal injection of PBS, $10 \mathrm{mM} 8 \mathrm{Br}$-cAMP, or $10 \mathrm{mM} 8 \mathrm{Br}-\mathrm{cAMP}+1 \mu \mathrm{g} / \mu \mathrm{L} 4 \mathrm{lg}(\mathrm{a}$ neogenin function-blocking peptide). Eyes were harvested on P12 and cryosectioned, and TUNEL staining was performed. (D) Representative TUNEL (red) images along with a nuclear stain (DAPI; blue) for each treatment group. Scale bars: $20 \mu \mathrm{m}$. (E) Quantification of data from $\mathbf{D}$. 8Br-cAMP ( $n=6$ ) led to a significant increase in the number of TUNEL-positive cells in the ONL compared with PBS treatment $\left(n=4,{ }^{* *} P<0.01\right)$, which was prevented by coadministration of $4 \lg \left(n=4 ;{ }^{*} P<0.05\right.$ compared with 8Br-cAMP). Significance determined using 1-way ANOVA followed by Šidák's multiple-comparisons test.

We then studied neogenin-protein levels in WT (C57BL/6J) mice following intravitreal injection of $10 \mathrm{mM} 8 \mathrm{Br}$-cAMP. Analysis was done using immunohistochemistry to allow for more accurate observation of expression changes within different retinal layers and cell types (24). cAMP injection resulted in a significant increase in retinal neogenin protein signal 72 hours later, seen predominantly in the inner and outer segments of the photoreceptors (Figure 1, C-E), as well as an increase in a subset of photoreceptor cell soma (Figure 2A). This contrasted with control-treated WT retinas, which displayed little neogenin staining in photoreceptors. In 8Br-cAMP-treated eyes, a moderate increase in neogenin levels could also be observed in Müller glia, but not bipolar cells, within the inner nuclear layer (INL) (Supplemental Figure 2). In situ hybridization experiments confirmed markedly increased neogenin mRNA levels where present in photoreceptor segments in 8Br-cAMP-treated retinas (Figure 2, B and C).

As previously described (17), we also observed an increase in TUNEL-positive photoreceptors following intravitreal injection of $8 \mathrm{Br}$-cAMP in WT mice (Figure 2, D and E), indicating that elevated cAMP is sufficient to promote photoreceptor cell death. TUNEL-positive cells could also be observed in the INL following 8Br-cAMP administration (Figure 2D), possibly relating to the increased neogenin observed in Müller glia (Supplemental 
A
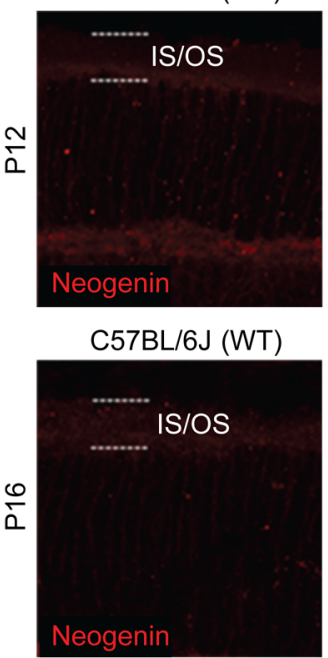

C57BL/6J (WT)

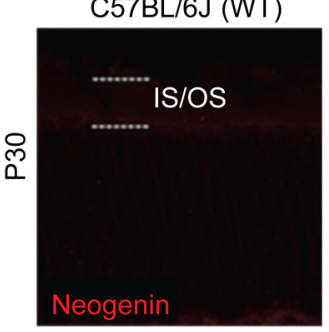

C

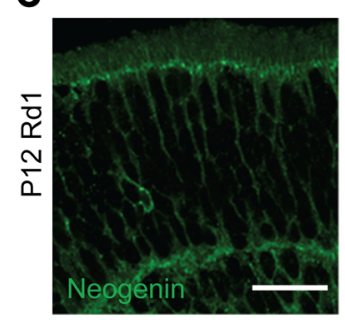

Rd1

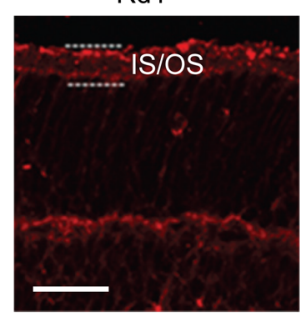

Rd1

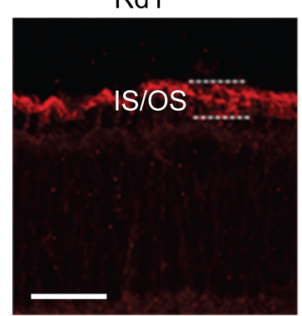

$\operatorname{Rd} 10$
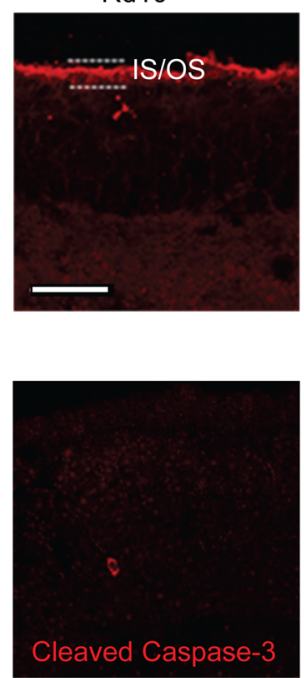

B

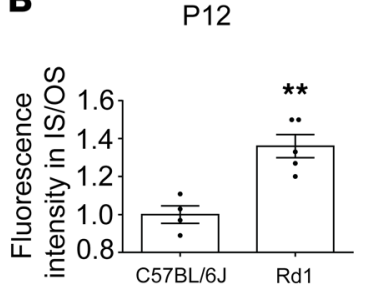

P16
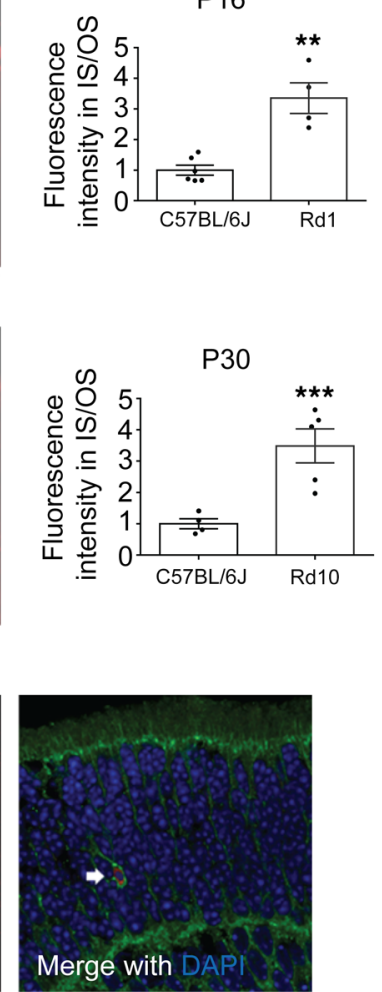

D

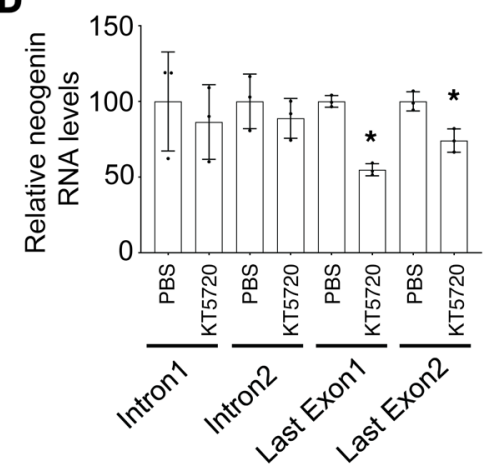

E

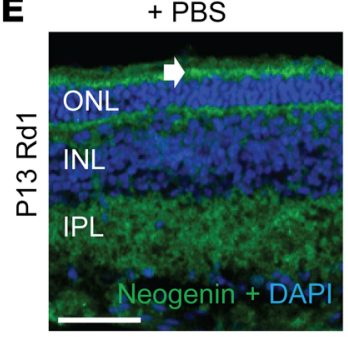

F

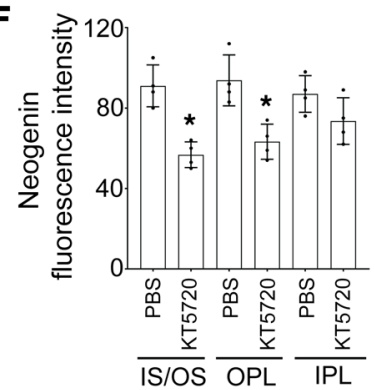

Figure 3. Elevated neogenin expression in Rd1 and Rd10 photoreceptors. (A) Representative images of cryosectioned C57BL/6) (WT) retina, and Rd1 or Rd10 retina immunostained for neogenin (red) on P12, P16, or P30. Dashed lines indicate border of the IS/OS. Scale bars: $30 \mu \mathrm{m}$. All images were taken under identical conditions/settings. (B) Quantification of data from A. Neogenin intensity levels were significantly increased in the IS/OS of P12/P16 Rd1 and P30 Rd10 when compared with WT mice of the same age. P12: $n=4$ and $n=5 ;$ P16 $n=4$ and $n=5 ;$ P30 $n=6$ and $n=4 .{ }^{* *} P<0.01$, ${ }^{* *} P<0.001$. Significance determined by Student's $t$ test. (C) Representative image of a P12 Rd1 ONL demonstrating coexpression of neogenin (green) and cleaved caspase-3 (red) in the same cell (white arrows). Nuclear stain appears in blue (DAPI). Scale bar: $20 \mu \mathrm{m}$. (D-F) PKA inhibitor KT5720 suppresses neogenin expression in Rd1 retinal photoreceptor segments. P12 Rd1 mice received an intravitreal injection of either 4 mM KT5720 or PBS and were harvested on P13 for analysis. (D) Realtime PCR of intron 1, intron 2, and the last exon of neogenin from the indicated treatments $\left(n=3 ;{ }^{*} P<0.05\right)$. Significance determined by Student's $t$ test. (E) Nuclear (DAPI, blue) and neogenin (green) staining of retinal sections from the indicated treatments. Scale bar: $50 \mu \mathrm{m}$. White arrows indicate neogenin in IS/OS. OPL, outer plexiform layer. (F) Quantification of data from E. Significance determined by Student's $t$ test $\left(n=4\right.$ for each; $\left.{ }^{*} P<0.05\right)$.

Figure 2). Previously we developed a peptide termed 4 Ig that prevents neogenin translocation into lipid rafts, thereby blocking its pro-death activity $(22,25)$. Coinjection of $8 \mathrm{Br}$-cAMP with 4Ig led to a significant reduction in TUNEL-positive photoreceptor cells, suggesting that neogenin is a major effector of cAMP-induced photoreceptor cell death (Figure 2E). Therefore, in order to confirm a direct role for cAMP on photoreceptors, we prepared dissociated cultures of murine rod photoreceptors and demonstrated that treatment with $1 \mathrm{mM} 8 \mathrm{Br}$-cAMP for 72 hours resulted in an increased percentage of photoreceptors express- ing cleaved caspase-3, an effect that was completely blocked through addition of $4 \operatorname{Ig}$ (Supplemental Figure 1, B and C).

Photoreceptor neogenin levels are elevated in murine and human retinas with IRD. Next, we investigated whether neogenin may be relevant for photoreceptor cell death in animal models of IRD. The Rd1 mouse, which is the most extensively studied model of RP (26), harbors a nonsense mutation in the gene coding for the $\beta$ subunit of rod cGMP PDE6 (27), rendering rod PDE nonfunctional. The Rd1 retinal phenotype is characterized by the onset of rod cell death by P9, followed by rapid degeneration peaking shortly after eye open- 
A Neogenin

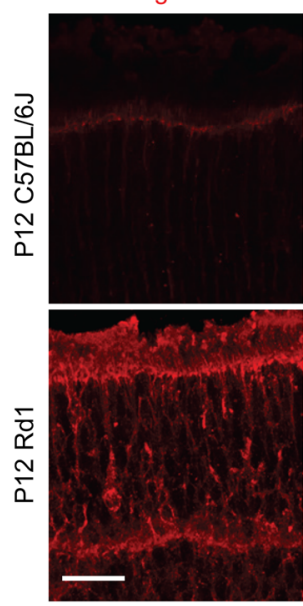

C

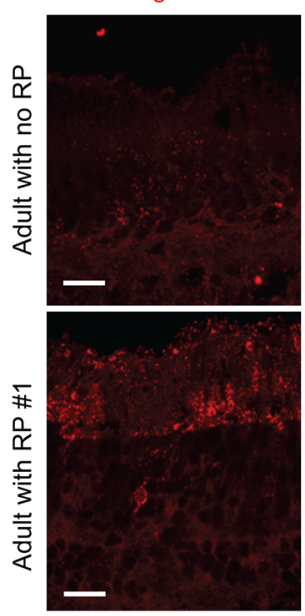

Rhodopsin

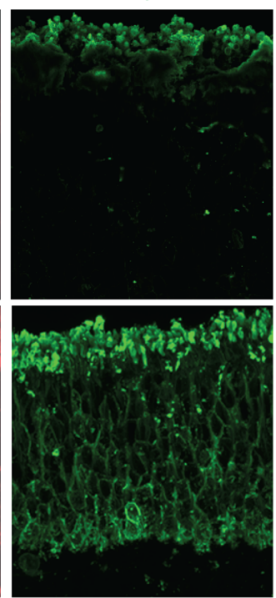

Rhodopsin

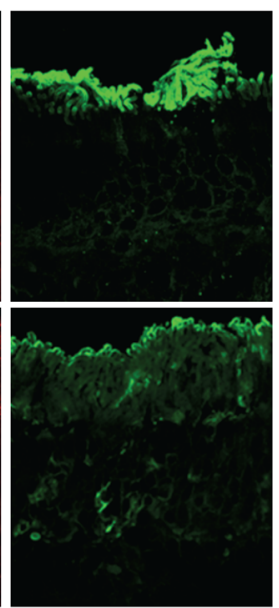

Merge with DAPI

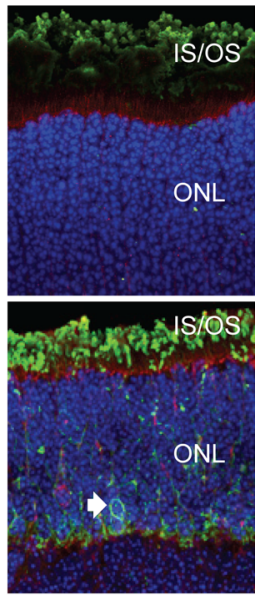

Merge with DAPI
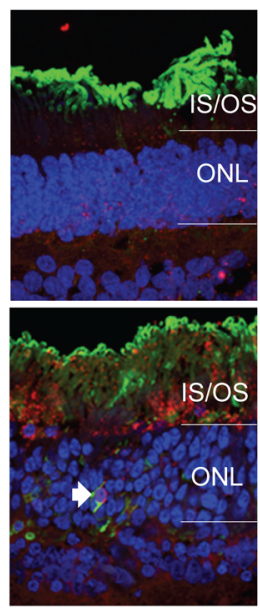

B
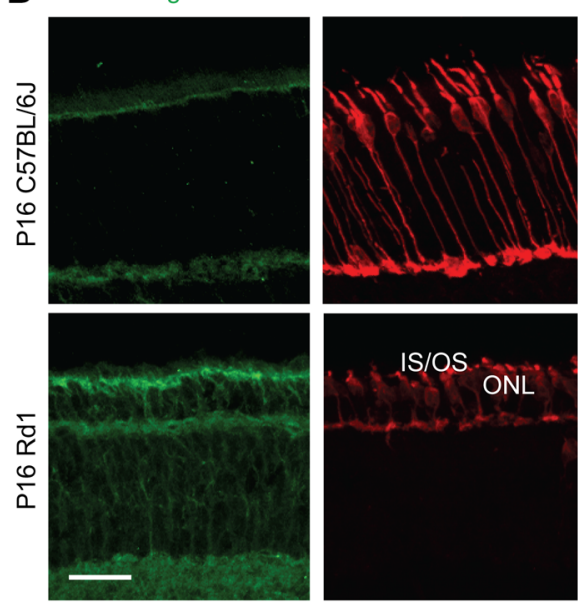

Merge with DAPI
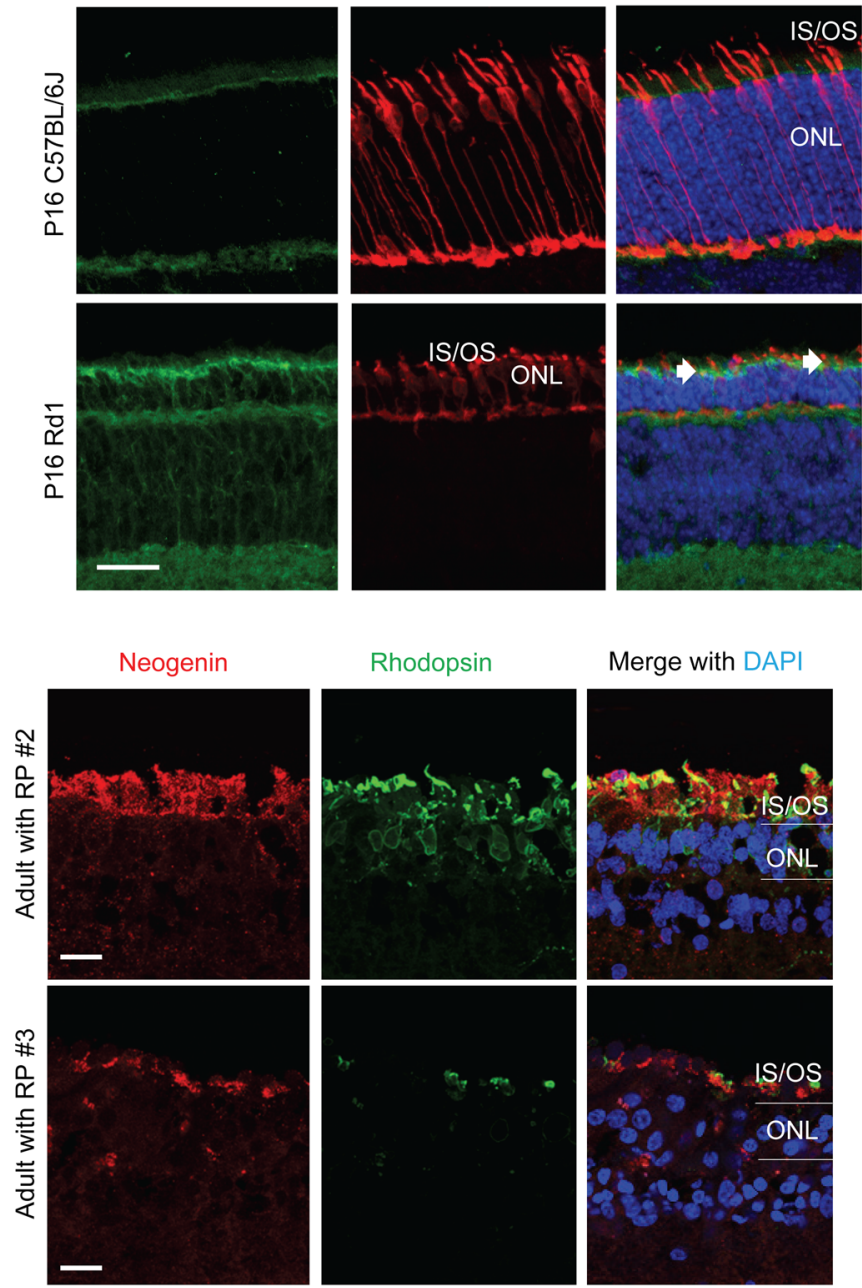

Rhodopsin

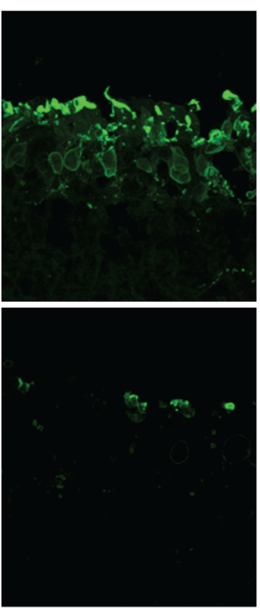

Merge with DAPI

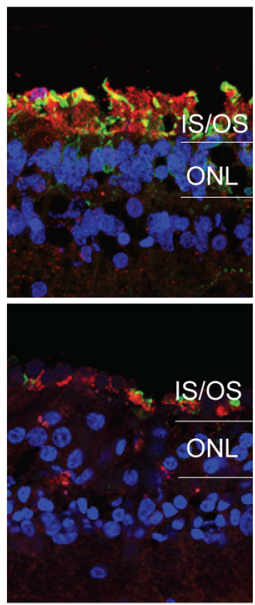

Figure 4. Neogenin induction in degenerating Rd1 rods, Rd1 cones, and human photoreceptors. (A) Representative immunostained cryosections of P12 C57BL/6) mouse retina or Rd1 mouse retina stained for neogenin (red), rhodopsin (green), and nuclei (DAPI; blue). In C57BL/6) retina, neogenin expression is largely restricted to the outer limiting membrane, with rhodopsin localized predominantly in the outer segments. In Rd1 mice, rhodopsin is misexpressed in the cell bodies of rods and is coexpressed in the same cells with neogenin (arrow). Scale bar: $20 \mu \mathrm{m}$. (B) Representative images of P16 C57BL/6) retina and P16 Rd1 retina. At this stage, cone degeneration has commenced in Rd1 mice, and the increased neogenin (green) expression in photoreceptors is also observed in cells staining positive for a marker of cones (Cone Arrestin; red). Arrows indicate examples of colabeling. Dashed lines indicate the borders of the ONL. Note the reduction in the size of the ONL at this age in Rd1 mice due to the majority of rods being gone. Scale bar: $20 \mu \mathrm{m}$. (C) Representative immunostained cryosections of retinas of a postmortem 54-year-old human donor not diagnosed with RP (Adult with no RP), a 63-year-old adult diagnosed with RP (Adult with RP \#1), a 64-year-old adult donor diagnosed with RP (Adult with RP \#2), and a 66-year-old adult donor diagnosed with RP (Adult with RP \#3). Sections were stained for neogenin (red), rhodopsin (green), and nuclei (DAPI; blue). Note the presence of neogenin in the IS/OS in the diseased retinas. Arrow indicates expression of neogenin and misexpressed rhodopsin in the same cell. Scale bars: $20 \mu \mathrm{m}$.

ing between ages P12 and P14 (28). Secondary cone loss begins shortly after the initial peak of rod apoptosis ( P15), and the majority of cones in the ONL are gone by P30 (29). Rd1 retina displayed elevated neogenin levels in the inner/outer segments of photoreceptors on $\mathrm{P} 12$ compared with age-matched WT retina, which was similar to the effect of 8Br-cAMP injection into WT eyes (Figure 3, A and B). Distinct neogenin expression was also observed in the cell soma of a subset of P12 Rd1 rod photoreceptors in the ONL (Supplemental Figure 3A), a phenomenon also observed in WT retina treated with 8Br-cAMP (Figure 2A) but not in WT control retina. In limited instances, cells with this soma expression pattern also stained positive for markers of cell death (Figure 3C), suggesting that, similar to what was observed in dissociated murine photoreceptors treated with $8 \mathrm{Br}$-cAMP, here there may also have been a link between elevated soma neogenin and terminal photoreceptor death.

The photoreceptor-specific increase in neogenin persisted at later stages of degeneration (Figure 3, A and B), and on P16, when cone photoreceptors start dying, increased neogenin expression could also be observed in the inner/outer segments of these cells (Figure 4B). Thus, elevated neogenin was not specific to cells expressing abnormal rod PDE but rather may have been a more generalized response of photoreceptors that were undergoing stress. Indeed, elevated neogenin in the ONL and inner/outer segments could also be seen in a mouse model of IRD that is independent of a PDE6 mutation, namely rhodopsin $\mathrm{P} 23 \mathrm{H}-$ knockin $\left(\mathrm{Rho}^{\mathrm{P} 23 \mathrm{H} / \mathrm{P} 23 \mathrm{H}}\right)$ mice (ref. 30 and Supplemental Figure $\left.3 \mathrm{~B}\right)$. 

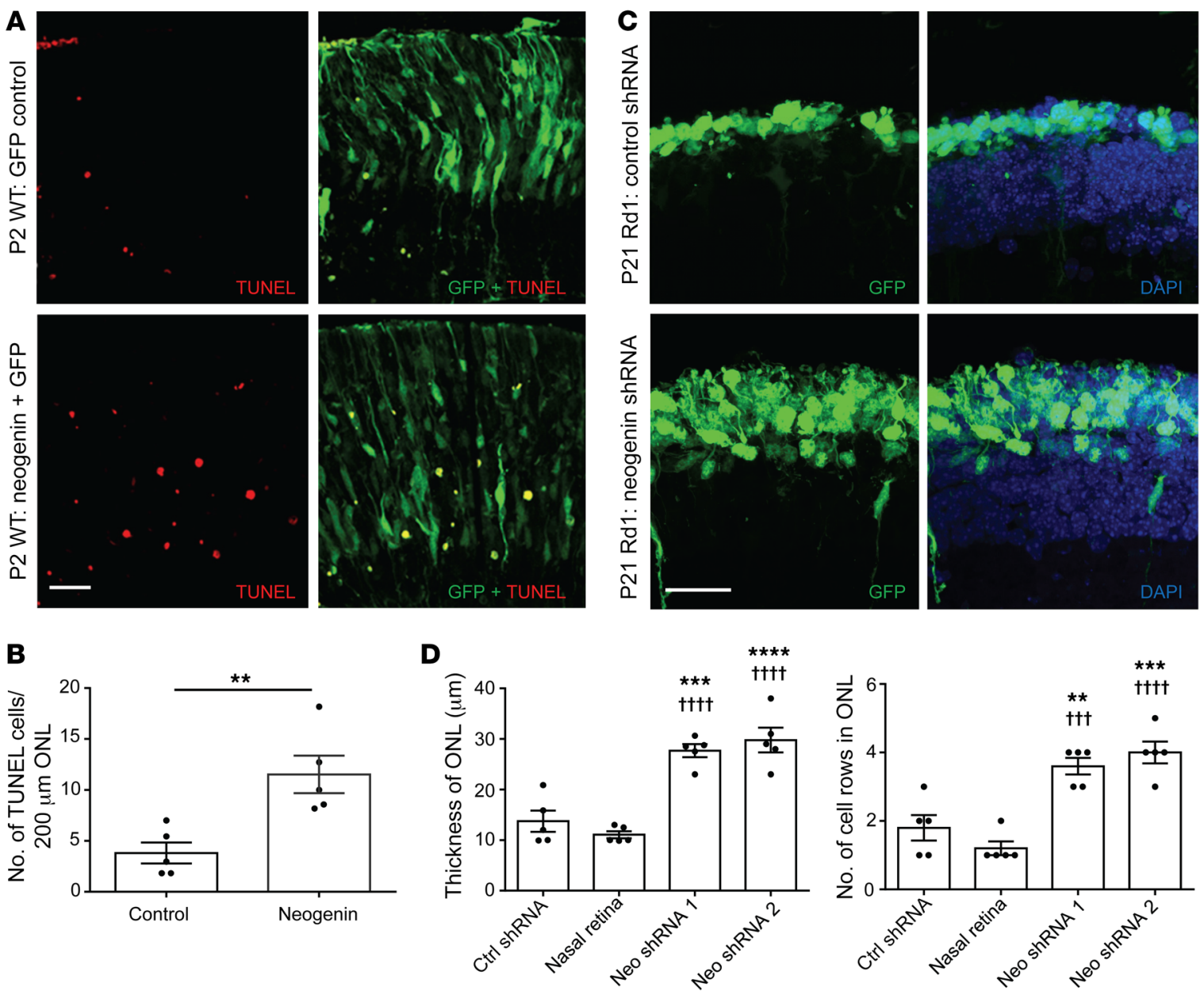

Figure 5. Neogenin is sufficient and required to induce photoreceptor cell death. (A) Temporal retinas of P0 C57BL/6] (WT) mice were electroporated with a full-length neogenin plasmid (pCDNA3-hNeogenin + GFP) or with a control plasmid (pEGFP). Eyes were harvested 2 days later, and TUNEL staining (red) was performed. GFP (green) indicates electroporated cells. Scale bar: $20 \mu \mathrm{m}$. (B) Quantification of data from A. The number of TUNEL-positive cells per $200-\mu \mathrm{m}$ length of electroporated retina was measured from 3 sections per eye and averaged. $n=5$ for each; ${ }^{* *} P<0.01$. Significance determined by Student's $t$ test. (C) Temporal retinas of PO Rd1 mice were electroporated with either scrambled shRNA or shRNA against neogenin, and mice were sacrificed on P21. GFP indicates electroporated cells. DAPI (blue) is a nuclear stain. Dashed lines indicate border of ONL. Scale bar: $20 \mu \mathrm{m}$. (D) Quantification of data from C. When compared with either control (scrambled shRNA) electroporated or the non-electroporated side (nasal retina), 2 separate neogenin shRNAs led to a significant increase in thickness of the ONL. $n=5$ for each. ${ }^{* *} P<0.01,{ }^{* *} P<0.001,{ }^{* * * *} P<0.0001$ compared with control shRNA; ${ }^{+t+} P<0.001$, ${ }^{+t+t} P<0.0001$ compared with nasal retina. Significance determined by 1-way ANOVA followed by Šidák's multiple-comparisons test.

Rd10 mice, like Rd1, also have a mutation in the rod-specific $\beta$ subunit of PDE6, but here it is a missense mutation that does not completely disable PDE6, leading to more gradual degeneration starting on P18-P20 and peaking sometime after P25 (31). A significant increase in neogenin signal in the inner/outer segments of photoreceptors could be observed on P30 (Figure 3, A and B), when photoreceptor degeneration is well underway (32), similar to our findings in the Rd1 model.

The pattern of this neogenin increase contrasts with photoreceptor cGMP levels in Rd1 mice, which rise abnormally during early stages of the disease (P6-P12), before dropping dramatically prior to the initiation of cell death (33). Instead, the neogenin temporal pattern bears more similarity to cAMP in Rd1 retina, wherein abnormally elevated adenylyl cyclase activity occurs by P7 (16) and abnormally high cAMP is seen by P9 and persists over time (16). As mentioned, in WT mice 8Br-cAMP administration led to a 2-fold increase in neogenin mRNA levels in photoreceptor segments (Figure 2C), along with elevated protein expression (Figure $1 \mathrm{E})$ and increased photoreceptor cell death (Figure 2E). We therefore sought to investigate whether the CAMP/PKA pathway also regulates neogenin in the degenerating retina. Here we performed intravitreal injection in Rd1 mice of the PKA inhibitor KT5720 (4 $\mathrm{mM}$ ) on P12 and observed significantly reduced neogenin levels in photoreceptor inner/outer segments 24 hours following injection (Figure 3, E and F). Examination of mRNA levels with real-time PCR further demonstrate that PKA inhibition reduced neogenin mRNA in the Rd1 retina (Figure 3D). These changes were detected with exonic but not intronic primers, implicating altered mRNA stability rather than transcription.

In support of the generalizability of elevated neogenin in degenerating photoreceptors, we also observed elevated neogenin in photoreceptor inner/outer segments in human postmortem 
$\mathbf{A}$

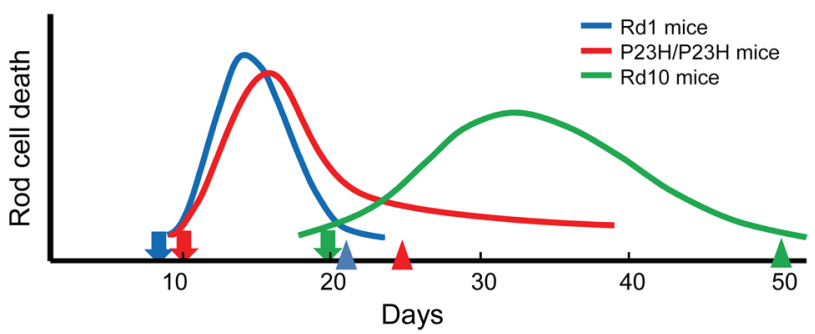

B

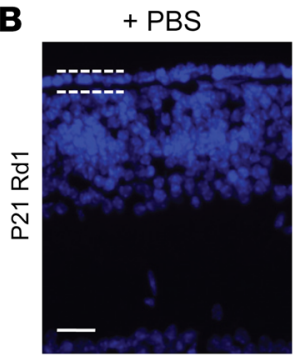

$+4 \lg$

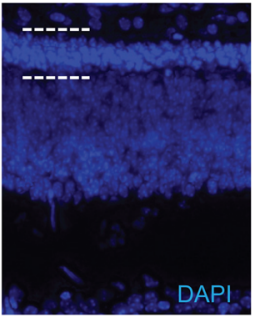

C

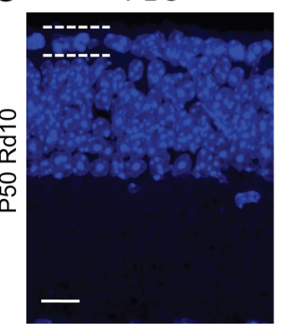

$+4 \lg$

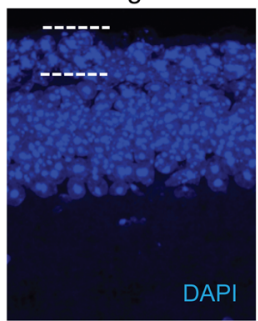

D

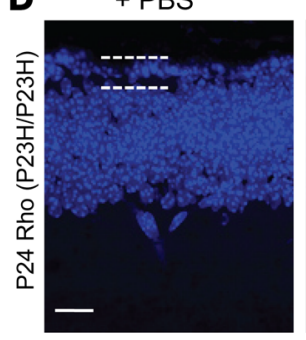

$\mathbf{E}$

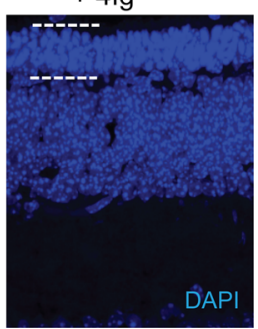

P21 Rd1

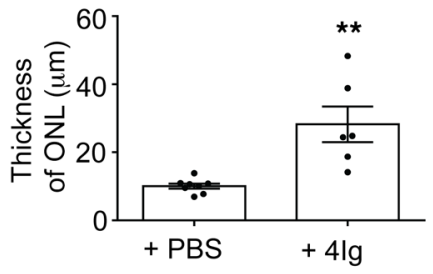

F

P50 Rd10
G P24 Rho (P23H/P23H)
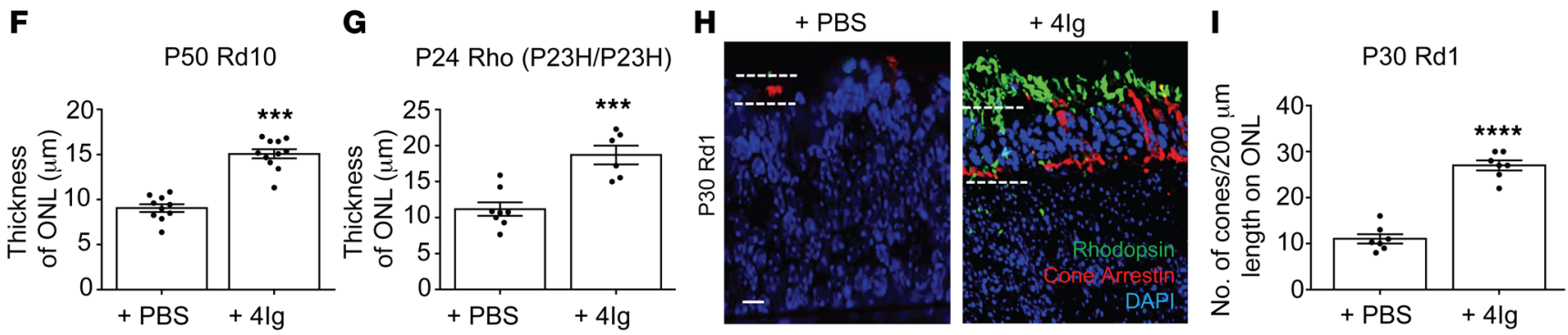

J

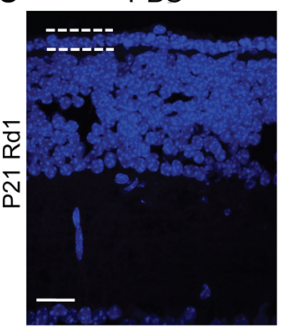

+ CNTF

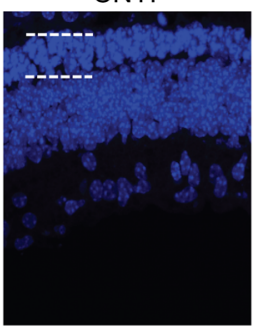

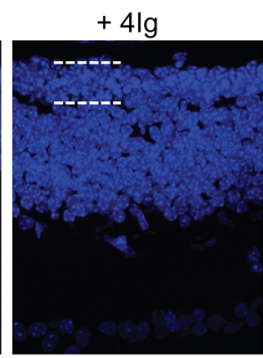

K

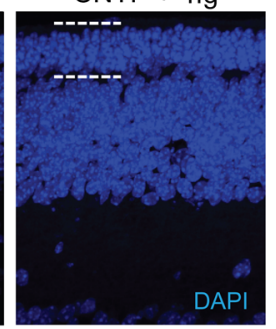

P21 Rd1

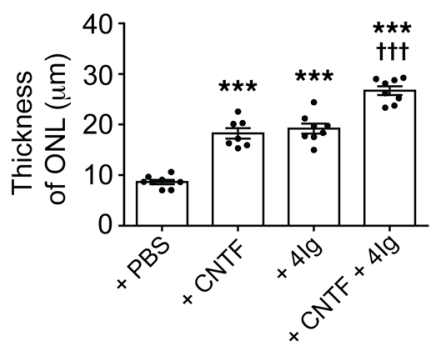

Figure 6. Blocking neogenin promotes photoreceptor survival. (A) Timing of rod death in the mouse models used. Arrows indicate timing of the initial treatment. Arrowheads indicate tissue harvest. (B-D) Representative DAPI images taken $400 \mu \mathrm{m}$ from the optic nerve head (ONH). Scale bar: $20 \mu \mathrm{m}$. Dashed lines indicate ONL borders. (B) Rd1 retina injected with 4/g $(1 \mu \mathrm{g} / \mu \mathrm{L})$ or PBS on P9 and P15 and harvested on P21. (C) Rd10 retina injected with $4 \mathrm{Ig}$ $(1 \mu \mathrm{g} / \mu \mathrm{L})$ or PBS on P20, P30, and P40 and harvested on P50. (D) Rho ${ }^{\mathrm{P} 23 \mathrm{H} / \mathrm{P} 23 \mathrm{H}}$ retina injected with $4 \mathrm{Ig}(1 \mu \mathrm{g} / \mu \mathrm{L})$ or PBS on P10 and harvested on P24. (E-C) Quantification of data from B and C. ONL size was measured in the nasal and temporal retina at $400 \mu \mathrm{m}$ from the ONH and averaged. $n=8$ and $n=6$ for

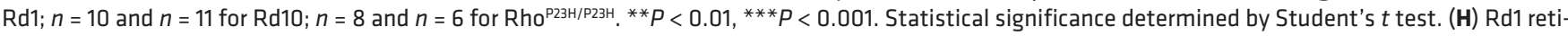
na treated with PBS or $4 \lg (1 \mu \mathrm{g} / \mu \mathrm{L}$ ) as above and harvested on P30. Representative images stained for rods (Rhodopsin), cones (Cone Arrestin) and DAPI. Dashed lines indicate ONL borders. Scale bar: $10 \mu \mathrm{m}$. (I) Quantification of data from $\mathbf{H}$ demonstrating that $4 \mathrm{lg}$ increased cone numbers. Measurements were made in nasal and temporal quadrants of the central retina and averaged. $n=7$ for each; ${ }^{* * *} P<0.0001$. Significance determined by Student's $t$ test. (J and K) Rd1 retina injected on P9 and P15 with PBS, CNTF $(0.8 \mu \mathrm{g} / \mu \mathrm{L}), 4 \lg (0.5 \mu \mathrm{g} / \mu \mathrm{L})$, or CNTF $(0.8 \mu \mathrm{g} / \mu \mathrm{L})+4 \mathrm{lg}(0.5 \mu \mathrm{g} / \mu \mathrm{L})$ and harvested on P21. (J) Representative DAPI images of P21 Rd1 retina. Scale bar: $20 \mu \mathrm{m}$. Dashed lines indicate ONL borders. (K) Quantification of data from J. 4lg $(n=8)$, CNTF $(n=7)$, and CNTF $+4 \lg (n=8)$ significantly increased the ONL thickness versus PBS $\left(n=8 ;{ }^{* *} P<0.001\right)$. CNTF +4 lg significantly increased thickness versus 4 Ig or CNTF ( $\left.{ }^{+t+} P<0.001\right)$. Significance determined by 1-way ANOVA followed by Bonferroni's test.

retina samples from 4 adults diagnosed with RP and 1 infant diagnosed with infantile Batten disease, a rare genetic disorder that can be considered a form of syndromic IRD (ref. 34, Figure 4C, and Supplemental Figure 4). Interestingly, in some of the human IRD samples, we also observed elevated neogenin in the soma of photoreceptor cells that also displayed a high level of somatic rhodopsin (Figure 4C, Adult with RP \#1), similar to what was seen in Rd1 mice (Figure 4A). This elevated neogenin in degenerating retinas con- 
A
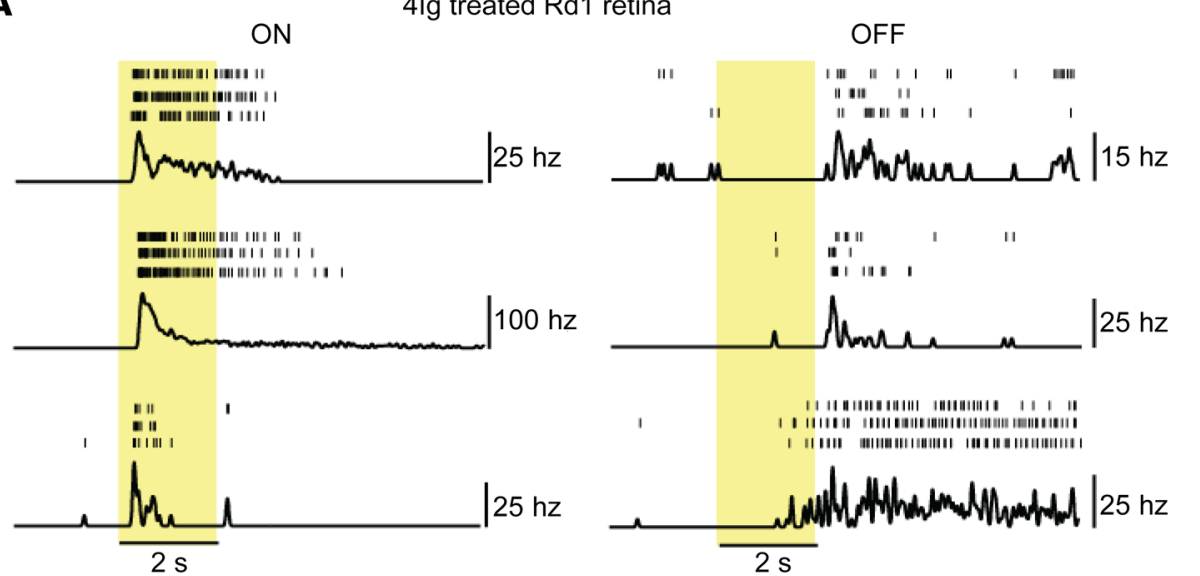

B

B Control Rd1 retina

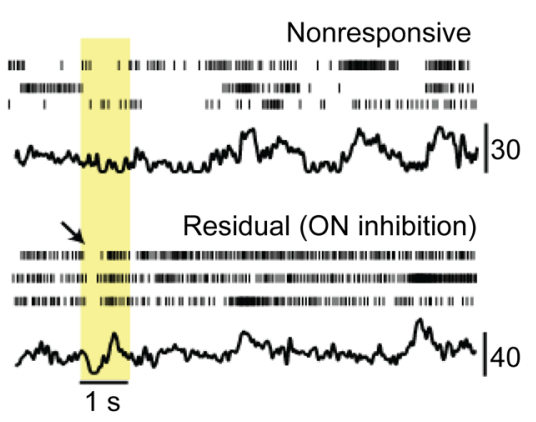

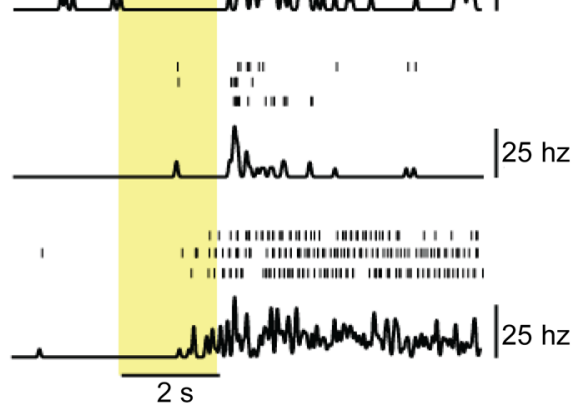

C

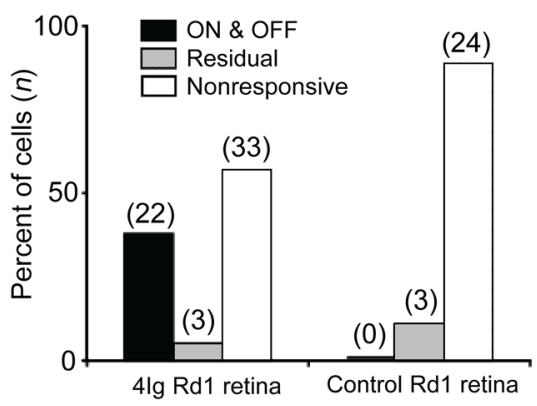

$\mathbf{E}$

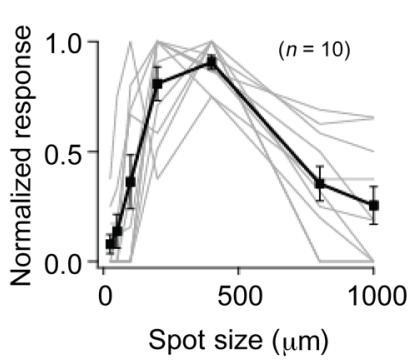

Figure 7. Improved feature detection in 4lg-treated Rd1 eyes. Rd1 mice were treated with $4 \lg (1 \mu \mathrm{g} / \mu \mathrm{L})$ on P8 and P13. Controls consisted of untreated age-matched Rd1 mice. Light-evoked activity in RGCs was recorded extracellularly using a patch electrode on P29-P35. (A) Spike rasters from 3 ON (left) and 3 OFF (right) RGCs in 4lg-treated $\mathrm{Rd} 1 \mathrm{retina}$. Shaded region indicates the duration of the stimulus (200- to $400-\mu \mathrm{m}$ spot). Black traces below the rasters show average spike rate estimated by Gaussian convolution $(\sigma=50 \mathrm{~ms})$. (B) Spike recordings from 2 example RGCs in control Rd1 retina illustrating the high spontaneous spike hyperactivity typically associated with photoreceptor degeneration. The bottom recording depicts the suppression of spiking at onset of light (arrow), indicating a weak residual photoreceptor response in untreated Rd1 animals. (C) A comparison of the relative population of the 3 cell types - ON and OFF, residual, and nonresponsive - in 4lg-treated and control retina. (D) The center-surround organization of RGCs is preserved in the 4lg-treated retina. The light response of an example $\mathrm{ON}$ ganglion cell to increasing spot sizes is shown. (E) The average peak responses of $10 \mathrm{ON}$ and OFF RGCs to increasing spot sizes shown in $\mathbf{D}$. The responses were significantly suppressed for spots larger than $400 \mu \mathrm{m}(P<0.001)$. (F) The response of an $\mathrm{ON}$ neuron to a $200-\mu \mathrm{m}$ spot moving in 8 different directions (indicated by the arrows; velocity, $0.6 \mathrm{~mm} / \mathrm{s}$ ). (G) A polar plot of the responses shown in $\mathbf{F}$. The responses of individual trials are shown in gray and the average in black. The direction selective index (DSI) is indicated by the solid radial line. DSI = $0.62 \pm 0.07$; value of 1 indicates responses to motion in only 1 direction.

$\mathbf{F}$

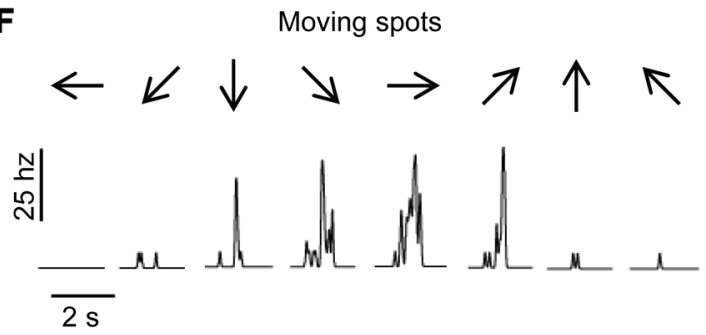

G

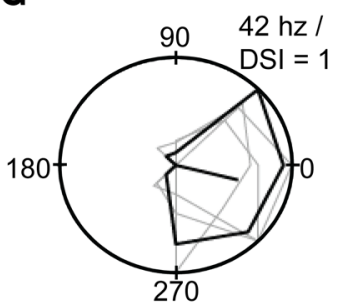

trasted with the nondiseased human retina, where neogenin photoreceptor expression was very low, similar to what was seen both in WT adult rat (35) and the WT mouse retina (Figure 1C).

Neogenin mediates photoreceptor death in RP mice. Neogenin triggers cell death in a variety of neural cell types, in particular following injury $(22,36)$. To determine whether elevated neogenin is also sufficient to induce photoreceptor death, we performed targeted in vivo electroporation of a neogenin overexpression construct in WT (C57BL/6J) P0-P1 mouse retina. Subretinal injection followed by electroporation of neonatal murine retina efficiently transduces dividing cells, leaving postmitotic cells unaffected, with most of the targeted cells generated from the newborn progenitors being rod photoreceptors (37). Two days after electroporation, retinas were collected, and TUNEL staining was performed. Although electroporation of a control plasmid in the eye generated few TUNEL-positive cells, electroporation of neogenin significantly increased cell death (Figure 5, A and B). When neogenin is unbound to its ligand, it can act as a dependence receptor by directly inducing cell death via proteolytic cleavage of its intracellular domain in order to expose a caspase activation site (38). Electroporation of a noncleavable form of neogenin compared with the WT form resulted in significantly reduced death, suggest- 
A
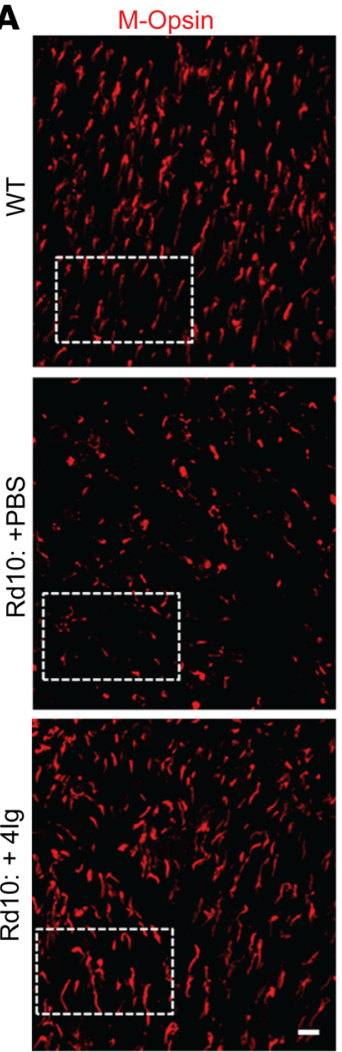
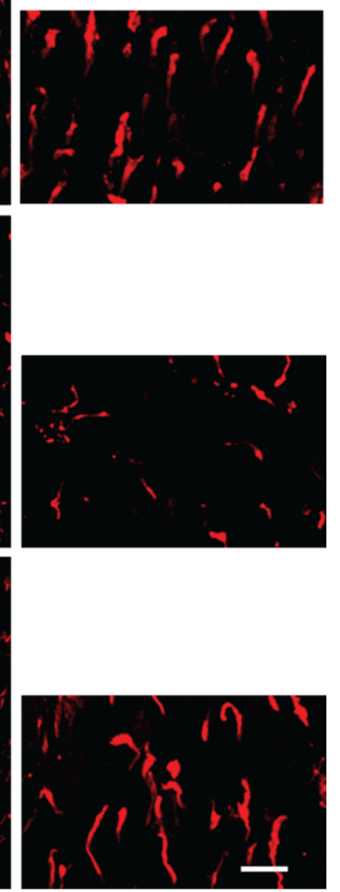

B

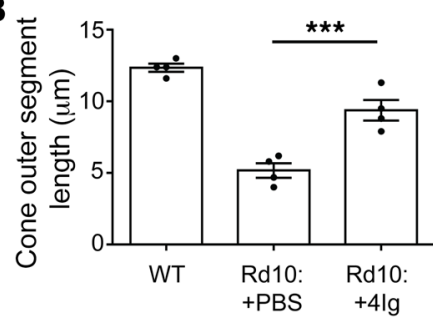

D

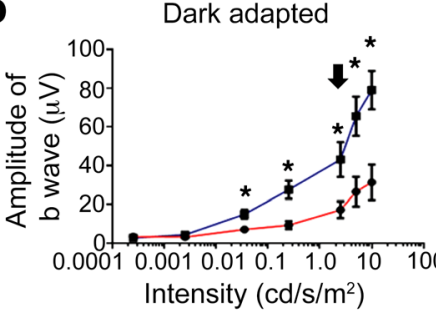

E

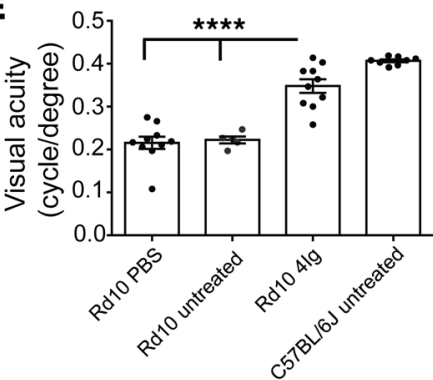

C

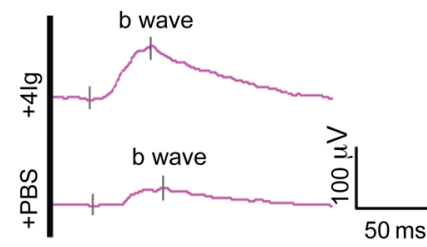

P30 Rd10: $5 \mathrm{~cd} / \mathrm{s} / \mathrm{m}^{2}$
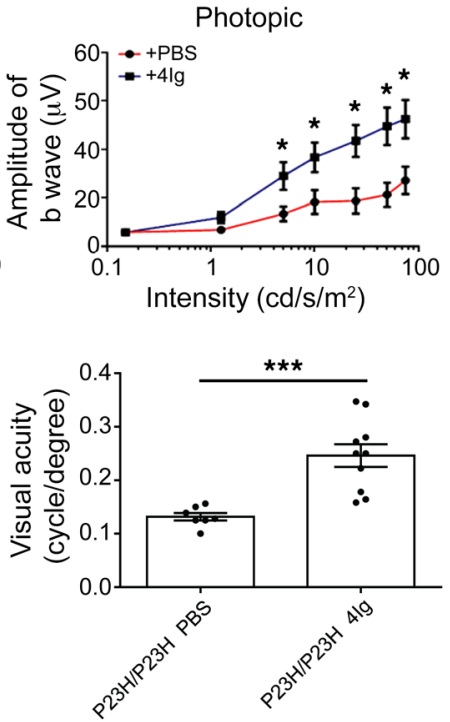

Figure 8. Improved visual function in 4Ig-treated Rd10 and Rho ${ }^{\mathbf{P 2 3 H} / \mathrm{P}_{23 \mathrm{H}}}$ mice. (A) Rd10 mice were treated with either PBS or $4 \mathrm{Ig}(1 \mu \mathrm{g} / \mu \mathrm{L})$ on P2O. Representative images of P30 retinal flat mounts of WT (C57BL/6)), 4lg-treated Rd10, or PBS-treated Rd10 mice stained with M opsin to label cone outer segments. Images are of the dorsal retina $600 \mu \mathrm{m}$ from optic nerve head. Scale bars: $10 \mu \mathrm{m}$. (B) Quantification of data from A. $4 \mathrm{lg}$ treatment led to a significant increase in the length of cone outer segments compared with PBS-treated Rd10 eyes $\left(n=4\right.$ for each; $\left.{ }^{* * *} P<0.001\right)$. Significance determined by 1-way ANOVA with Tukey's multiple-comparisons test. (C) Representative electroretinogram (ERG) traces from P30 Rd10 mice treated on P20 with either PBS or $4 \lg (1 \mu \mathrm{g} / \mu \mathrm{L})$. Traces were taken under photopic conditions at $5 \mathrm{~cd} / \mathrm{s} / \mathrm{m}^{2}$. (D) Quantification of b wave amplitude of $4 \mid \mathrm{g}$ - or PBS-treated Rd10 mice under dark-adapted (scotopic) and light-adapted (photopic) conditions. Black arrow indicates beginning of flash intensities eliciting mixed rod/cone responses. 4lg treatment significantly increased b wave amplitudes for rod-driven, mixed rod/cone-driven, and cone-driven responses ( $n=7$ for each; ${ }^{*} P<$ 0.05). Significance determined by 2-way ANOVA with Bonferroni's correction for multiple comparisons. (E) Left: Visual acuity was significantly improved in Rd10 mice on P28 following 4Ig injection $(1 \mu \mathrm{g} / \mu \mathrm{L})$ on P20 when compared with PBS-treated Rd10 mice. Visual acuity assessed by measuring optokinetic tracking response thresholds using the OptoMotry system $\left(n=10\right.$ for each; $\left.{ }^{* * *} P<0.0001\right)$. Significance determined by 1-way ANOVA followed by Bonferroni's multiple-comparisons test. Right: Visual acuity was significantly improved in Rho ${ }^{\mathrm{P} 23 \mathrm{H} / \mathrm{P} 23 \mathrm{H}}$ mice on P23 following $4 \mathrm{lg}$ injection on P10 ( $n=10 ; 1 \mu \mathrm{g} / \mu \mathrm{L}$ ) when compared with PBS controls $\left(n=7 ;{ }^{* * *} P<0.001\right)$. Significance determined by Student's $t$ test.

ing that cleavage is important for neogenin's pro-death effect in photoreceptors (Supplemental Figure 5, A and B).

We next investigated whether elevated neogenin levels in Rd1 retina are required for retinal degeneration. For this, 2 different prevalidated shRNAs against mouse neogenin were used to silence its expression in photoreceptors following in vivo electroporation on PO in Rd1 mice. Animals were sacrificed on $\mathrm{P} 21$, when the majority of rod photoreceptors are gone and the ONL is reduced to 1-2 cell layers. Silencing of neogenin dramatically rescued the number of surviving photoreceptors compared with control (scrambled shRNA) electroporated animals (Figure 5, C and D, and Supplemental Figure 5C). Together with the results of the overexpression experiments, this suggests that neogenin is both sufficient to promote photoreceptor death in WT photoreceptors and required for the rod photoreceptor cell death seen in Rd1 mice.
A peptide treatment strategy promotes photoreceptor survival and function. Given that in vivo electroporation only targets a limited portion of the retina, we sought an alternative neogenin neutralization approach that is both amenable for functional testing and also more therapeutically translatable for potential clinical use. One relevant method of retinal drug delivery is intravitreal injection of peptide-based compounds (39), which can penetrate deep layers of the retina (40). We therefore tested the neogenin-neutralizing $4 \mathrm{Ig}$ peptide, which we showed above to block cAMP-induced photoreceptor death (Figure 2, D and E, and Supplemental Figure 1, B and C). When Rd1 mice received an intravitreal injection of $4 \operatorname{Ig}(1 \mu \mathrm{g} /$ $\mu \mathrm{L}$ in PBS) or PBS (control) on P9 (coinciding with the commencement of rod cell death), there was a significant reduction in the number of TUNEL-positive cells in the ONL on P14 (Supplemental Figure 6, A and B). When Rd1 mice were given 2 intravitreal injections of $4 \mathrm{Ig}$, on $\mathrm{P} 9$ and P15, there was dramatic preservation of the 
number of surviving rod photoreceptors in the P21 retina (Figure 6, B and E, and Supplemental Figure 6, D and H). To confirm that this treatment approach has applicability in non-PDE-dependent models of IRD, we used $\mathrm{Rho}^{\mathrm{P} 23 \mathrm{H} / \mathrm{P} 23 \mathrm{H}}$ mice $(41,42)$. As described previously $(30,43)$, these mice experience rapid, severe rod degeneration shortly after eye opening, with the majority of rods gone by P24 (Figure 6A). As we had observed in Rd1 mice, intravitreal injection of $4 \mathrm{Ig}$ coinciding with the onset of retinal degeneration improved survival of ONL photoreceptors in $\mathrm{Rho}^{\mathrm{P} 23 \mathrm{H} / \mathrm{P} 23 \mathrm{H}}$ mice (Figure 6, D and G, and Supplemental Figure 6, G and H).

To test whether the 4Ig peptide supports survival over longer periods, and whether this translates into a corresponding improvement in the number of surviving cone photoreceptors, we treated Rd1 mice on P9 and P15 and then sacrificed them on P30. Here there was a significant increase in the number of surviving cones compared with controls (Figure 6, H and I), as well as maintenance of rhodopsin staining. Increased cone survival may reflect the direct action of the 4Ig peptide on cones and/or the secondary consequence of increased rod survival. To extend analysis over even longer periods, we assessed photoreceptor survival in Rd10 mice at advanced stages of degeneration. Intravitreal injections of 4Ig or PBS were performed on P20, P30, and P40, and mice were sacrificed on P50. Here photoreceptor survival was also improved following peptide-mediated neogenin function blockage (Figure 6, C and F, and Supplemental Figure 6, E, F, and H).

Ciliary neurotrophic factor (CNTF) is a polypeptide hormone that is a potent survival factor for neurons, and numerous studies have demonstrated CNTF's prosurvival effect on photoreceptor cells $(44,45)$. However, in addition to exerting beneficial effects on survival, intravitreal bolus administration of CNTF can lead to numerous unwanted functional, cytologic, and biochemical retinal alterations (44) that negatively impact visual functions (46). We therefore sought to determine how intravitreal injection of 4Ig compares with intravitreal injection of CNTF. Rd1 mice were injected on P9 and P15 with PBS, 4Ig alone $(0.5 \mu \mathrm{g} / \mu \mathrm{L})$, rat CNTF alone $(0.8 \mu \mathrm{g} / \mu \mathrm{L})$, or rat $\operatorname{CNTF}(0.8 \mu \mathrm{g} / \mu \mathrm{L})$ plus $4 \operatorname{Ig}(0.5 \mu \mathrm{g} / \mu \mathrm{L})$ in the vitreous. Eyes were then harvested on P21. Animals treated with 4Ig alone or CNTF alone showed roughly similar significantly increased levels of photoreceptor rescue compared with controls (Figure 6, J and $\mathrm{K}$ ). When the 2 treatments were combined, the ONL was thicker than with either treatment on its own, suggesting an additive effect and differing mechanisms of action. 4Ig alone or in combination with CNTF was also associated with reductions in adverse ocular parameters such as retinal thinning and cataract formation when compared with rat CNTF alone (Supplemental Figure 6C and Supplemental Table 1).

Given that some prosurvival compounds also impair the ability of photoreceptors to respond to light $(44,46-48)$, we sought to investigate whether $4 \mathrm{Ig}$ treatment promotes improvement in visual function. In the case of Rd1 mice, which present with rapid degeneration coupled with nonfunctional rods, we used the highly sensitive method of recording light-evoked spike activity in RGCs, which are the output neurons upon which photoreceptor activity converges. To demonstrate the effect of 4 Ig on light response, we used Rd1 mice older than P28, which corresponds to an age when photoreceptor-driven light-evoked RGC activity is absent (49, 50). Rd1 mice were treated with $4 \operatorname{Ig}(1 \mu \mathrm{g} / \mu \mathrm{L})$ on P8 and P14, and retinal whole mounts were prepared on P29-P35. Light-evoked spike activity was monitored extracellularly for individual neurons using a patch electrode, and for simplicity, all spiking neurons were referred to as RGCs. We observed robust light-evoked spike activity in 4Ig-treated but not control Rd1 retina in response to a bright spot (200- to 400- $\mu \mathrm{m}$ diameter) centered over the RGC soma (Figure 7, A and B). In 4Ig-treated retinas, robust responses were observed in approximately $40 \%$ of the RGC neurons tested (Figure 7C; average ON peak spike rate, $45 \pm 8 \mathrm{~Hz}$; OFF peak spike, $30 \pm 5 \mathrm{~Hz}$ ), which contrasts with control Rd1 retina, in which none $(0 \%)$ of the spiking RGC neurons displayed robust lightevoked responses (Figure 7, B and C). The light-evoked responses in 4Ig-treated retinas were completely eliminated when glutamate synaptic activity was blocked using AMPA/KA (10 $\mu \mathrm{M}$ cyanquixaline [CNQX]) and NMDA antagonists, and an mGluR6 agonist (50 $\mu \mathrm{M}$ DL-AP4; $n=9$; data not shown), indicating that these responses originated in the photoreceptors.

When 4Ig-treated retinas were probed with spot stimuli of increasing sizes, the typical center-surround organization (51, 52) was left intact (Figure 7, D and E). Spiking responses in RGCs increased up to an optimal size of approximately $400 \mu \mathrm{m}$, indicating the extent of the excitatory center. Further increases in stimulus size resulted in a reduction in activity due to the recruitment of the inhibitory surround. When we probed 2 ganglion cells with moving stimuli, we also found evidence for direction selectivity (DS); i.e., they responded to motion in certain "preferred" directions but not the opposite "null" directions (Figure 7, F and G). The remaining tested cells in the 4Ig-treated retinas were either nonresponsive to light stimuli or exhibited a weak light response, which manifested as a decrease in spike activity at light onset. These very weak, nonrobust, inhibitory responses were also observed in a small fraction of control Rd1 retina (Figure 7B), indicating that they were likely mediated by residual photoreceptor activity.

Following eye opening, Rd1 mice quickly begin to display abnormal inner retina circuit behavior. This is characterized by spontaneous hyperactivity of the RGCs beginning at the commencement of rod degeneration, greatly increasing between P15 and P21, and plateauing by P28 (49). At intermediate stages of degeneration (P14-P15), light-evoked responses can be seen in some RGCs together with the abnormal spontaneous hyperactive behavior. However, on P21 and P28 there are no robust lightevoked ganglion cell responses (49), and abnormal hyperactivity is severe. These high levels of spontaneous background hyperactivity were observed in all RGCs in the control Rd1 retina and also in light-insensitive cells in the 4Ig-treated retina (peak, $29 \pm 3 \mathrm{~Hz}$; $n=33$ ). In contrast, light-sensitive ganglion cells in the 4Ig-treated retina exhibited very low spontaneous background activity (peak, $6 \pm 2 \mathrm{~Hz} ; n=22 ; P<0.005$ compared with hyperactive RGCs), indicating that the rescue strategy used here does not require additional methods to reduce spontaneous hyperactivity in order to enhance the visual signals that are relayed to the brain. Sectioning of the 4Ig-treated Rd1 retina used here confirmed that photoreceptor survival was promoted (Supplemental Figure 7).

To further validate the functional benefits of this peptide treatment approach, we performed additional tests in Rd10 mice, which present with more gradual degeneration compared with Rd1 mice. In these mice, the morphology and length of cone outer segments 
becomes severely disturbed by P25, which is when these mice lose cone-driven light responses in electroretinograms (ERGs) (31, 32, 53). We therefore performed an intravitreal injection of 4Ig on P2O, followed by sacrifice on P30, and measured cone outer segment length, which was significantly improved compared with that in PBS-treated control Rd10 retina (Figure 8, A and B).

Visual function in Rd10 mice was assessed using ERGs, which measure the global electrical responses of various cell types (rods, cones, bipolar cells, Müller glia) in response to light stimuli. If the test is performed under dark-adapted (scotopic) conditions, dim light flashes initially evoke rod-driven electrical responses, and as the flash intensities increase, a mixed rod-cone response is generated. If the test is performed under light-adapted (photopic) conditions, flashes evoke a cone-driven response. The amplitude of the b wave is commonly used as an indicator of the quality of visual function in rodents (54). Rd10 mice were treated with 4Ig on P2O, and on P30 mice were dark adapted overnight and subsequently subjected to ERG recordings. This age corresponds to a time when cone-driven responses are largely absent $(31,32,53)$. Under scotopic conditions, treated mice showed a significant improvement in b wave amplitudes at flash intensities eliciting rod-driven responses and at intensities eliciting mixed rod/cone responses (Figure 8, $\mathrm{C}$ and D, and Supplemental Figure 8). Following light adaptation, there was also a significant improvement in cone-driven b wave amplitudes (Figure 8D), indicating an improvement in both rodand cone-driven visual function.

Behavioral measures of visual thresholds are another means of assessing visual function. In rodents, slow reflexive horizontal head and body rotation occurs when the visual field is rotated around them, and this optomotor tracking can be reliably produced in a virtual reality system known as OptoMotry $(55,56)$. In this procedure, a virtual cylinder covered with vertical sine wave gratings is presented to a mouse freely standing on a raised platform (56). The maximum spatial frequency that drives head movements is a measurement of visual acuity (in cycles/degree). The optomotor tracking response is due to the same subcortical visual pathways responsible for horizontal optokinetic nystagmus (55), is measurable after eye opening, and reaches peak acuity by P24 (56). Rd1 mice lacked this response, whereas PBS-treated P28 Rd10 and $\mathrm{P} 23 \mathrm{Rho}^{\mathrm{P} 23 \mathrm{H} / \mathrm{P} 23 \mathrm{H}}$ mice had impaired visual acuity, which was significantly improved following $4 \mathrm{Ig}$ treatment (Figure $8 \mathrm{E}$ ). Together, these data show that peptide inhibition of neogenin is a potential strategy to prevent the loss of visual function.

\section{Discussion}

Here we identify neogenin as a major regulator of photoreceptor death in retinal degeneration. We show that cAMP induces neogenin upregulation, which triggers photoreceptor death. In the human and the murine retina with IRD, we observed increased neogenin levels in photoreceptors when compared with healthy eyes. In models of IRD, neogenin inhibition prevented cone and rod death and preserved ERG responses and light-evoked retinal output, thereby stabilizing visual acuity. Thus, peptide-based neogenin inhibition represents a viable strategy to protect visual functions in retinal degeneration.

Despite the great genetic heterogeneity of IRDs, there are common pathological features that have been observed in different ani- mal models. For example, dysregulation of cyclic nucleotide signaling is a common feature of many IRD models $(57,58)$. Indeed, abnormal elevation of both cAMP and cGMP has been observed in numerous animal models of IRDs $(14,16)$. The notion that cAMP promotes photoreceptor death in IRDs is supported by findings that cAMP levels are abnormally elevated in numerous animal IRD models, such as $\mathrm{P} 23 \mathrm{H}$ rats and S334Ter rats (14), and P347S mice (15) and Rd2 mice (also known as Rds) $(57,58)$. Strategies used to lower cAMP levels also have had protective effects in various IRD models (e.g., Rd10) (59-61). The mechanisms by which cAMP contributes to photoreceptor death are largely unknown, though they likely involve PKA-mediated changes in gene expression $(62,63)$. Here we address this knowledge gap by uncovering a critical component of the death signaling pathway in models of IRD, whereby elevated levels of cAMP promote photoreceptor death by modulating the expression the dependence receptor neogenin.

Studies in mammalian cells have revealed that cAMP is instrumental in stabilizing select mRNAs $(64,65)$, which prompted us to investigate whether cAMP/PKA exerts any effect on neogenin mRNA levels and stability in IRD retinas. Our results suggest that cAMP levels are an important effector in the regulation of neogenin mRNA stability, though the specific mechanisms mediating this effect are not well defined. Previous studies have shown that cAMP/PKA can regulate mRNA stability by directly altering the activity of proteins involved in mRNA decay. For instance, cAMP-elicited phosphorylation of TIS11b, which targets some mRNAs for degradation, plays a key regulatory role in its mRNA decay-promoting function (66).

The finding that neogenin neutralization/silencing promoted photoreceptor survival in models of IRD suggests that dependence receptor inhibition represents an as-yet-unexplored treatment opportunity for these disorders. One means by which neogenin acts as a dependence receptor is by directly inducing cell death via proteolytic cleavage of its intracellular domain in order to expose a caspase cleavage site (38). Here we observed individual photoreceptors that stained positive for both elevated neogenin in their cell soma and for cleaved caspase-3 in P12 Rd1 mice, and furthermore found that a noncleavable mutant for neogenin had a reduction in pro-death function. In dissociated photoreceptor cultures, cAMP led to elevated cleaved caspase- 3 levels in photoreceptors, and this was completely blocked by neutralizing neogenin function. Although caspase- 3 has been shown to be involved in retinal degeneration in both $\mathrm{Rd} 1$ (67-69) and $\mathrm{Rd} 10$ mice (32), along with many other RP models $(67,70)$, others have argued that while potentially involved, it is not necessarily critical for retinal degeneration (71). In addition to direct involvement in caspase activation, neogenin also promotes cell death via death-associated protein kinase (DAPK) activation (72), which is a key regulator of pro-cell death pathways through both caspase-dependent and caspase-independent signals $(73,74)$. DAPK is a key component in the ER stress-induced cell death pathway (75), which has also been implicated in Rd1 photoreceptor degeneration (76). Thus, although our data suggest that caspase is involved in photoreceptor death in Rd1/10 mice, we cannot at this point exclude the involvement of nonapoptotic pathways downstream of neogenin.

In the Rd1 model of severe retinal degeneration, it is also notable that our treatment approach, in addition to promoting 
photoreceptor survival and visual processing within the retina, also abrogates abnormal circuit behavior. RGC hyperactivity is observed in numerous models of IRD and reflects stereotyped regressive inner retinal changes (77). These rhythmic outbursts are triggered by oscillatory synaptic inputs most likely driven by an electrically coupled network of ON cone bipolar and AII amacrine cells (78) and can impair residual visual function driven by surviving photoreceptors (79). The mechanisms underlying the abrogation of RGC hyperactivity seen here remain unknown (50), though likely they relate to the benefits of maintaining synaptic contacts between photoreceptors and retinal interneurons. Thus, neogenin inhibition prolongs normal retinal processing while also slowing the occurrence of regressive inner retinal changes, suggesting it could be a beneficial adjunct to approaches aimed at restoring or preventing degenerative vision loss in humans.

One IRD treatment approach currently being applied for humans is gene replacement therapy, which uses viral vectorbased gene delivery in order to express WT versions of the affected protein. For example, gene therapy has been used successfully for RPE65-related Leber congenital amaurosis (LCA2), a form of congenital childhood blindness with similarities to RP. However, after 4.5-6 years of follow-up, it was observed that the rate of photoreceptor death was the same in the patients' treated and untreated eyes (80), suggesting that even with gene therapy, additional approaches aimed at preventing further photoreceptor loss may be needed. One such approach under investigation involves the overexpression of histone deacetylase 4 (HDAC4) in order to prolong rod and cone survival in Rd1 mice, which leads to partial restoration of visual functions (81). Future work will determine whether this can lead to the generation of a protein-based therapy for IRDs. Another approach involves application of CNTF, which has been shown to slow photoreceptor degeneration in several animal models (82) but failed to demonstrate visual function benefits in human clinical trials (83). Besides providing an alternative to these therapeutic opportunities, the peptide treatment approach presented here demonstrated synergistic effects on photoreceptor survival when combined with CNTF. This suggests that synergistic therapies are possible in IRDs and paves the way for future treatment approaches in which multiple therapeutics are used together in order to achieve long-term vision protection.

\section{Methods}

Supplemental Methods are available online with this article.

Retinal degeneration mouse strains. $\mathrm{C} 3 \mathrm{H} / \mathrm{HeJ}$ (Pde6 $\mathrm{b}^{\text {rd1 }}$; The Jackson Laboratory), ICR (Pde6b ${ }^{\text {rd1 }}$; Taconic), B6.CXB1-Pde6b ${ }^{\text {rd10 }} / \mathrm{J}$ (Rd10; The Jackson Laboratory), B6.129S6(Cg)-Rhotm1.1Kpal/J (P23H; The Jackson Laboratory), B6.Cg-Tg(Nrl-EGFP)1Asw/J (The Jackson Laboratory), and C57BL/6J (The Jackson Laboratory) mice were used. All animals were handled according to guidelines and standard operating procedures of the University Health Network, Toronto, Ontario, Cana$\mathrm{da}$, and were housed under 12-hour light/12-hour dark cycles. Animals were bred using standard procedures.

$4 I g$ peptide preparation. The 4Ig construct was generated previously in our laboratory (22). Briefly, the 4 Ig domains of neogenin's extracellular domain were inserted into the polylinker region of pSecTag 2B (Thermo Fisher Scientific) such that a signal peptide was added to the
$\mathrm{N}$-terminal portion of the $4 \mathrm{Ig}$ peptide and a His-tag was added to the C-terminal portion of the peptide.

A HEK293 cell line (ATCC) stably expressing secreted Histagged 4Ig peptide was used for 4Ig generation. $10 \times$ binding solution consisted of sterile PBS containing $3 \mathrm{M} \mathrm{NaCl}, 50 \mathrm{mM}$ imidazole, $\mathrm{pH}$ 7.4, diluted 10-fold in the 4Ig-containing Opti-MEM supernatant. Approximately $150 \mu \mathrm{L}$ Nickel-NTA Agarose beads (QIAGEN) was added per $50-\mathrm{mL}$ solution, and the mixture was placed at $4^{\circ} \mathrm{C}$ with gentle rocking for 2 hours to allow for maximal protein binding. Beads were then washed 5-10 times with PBS plus $300 \mathrm{mM} \mathrm{NaCl}, 20$ $\mathrm{mM}$ imidazole, $\mathrm{pH}$ 7.5. Protein was eluted in PBS plus $300 \mathrm{mM} \mathrm{NaCl}$ plus $200 \mathrm{mM}$ imidazole, pH 7.5. $10 \mu \mathrm{L}$ eluate plus $2 \mu \mathrm{L} 6 \times$ Laemmli buffer was run on a $10 \%$ SDS gel. Following gel electrophoresis, a Coomassie stain was performed to assess protein purity. 4Ig runs at approximately $70 \mathrm{kDa}$. Protein from the eluate was then concentrated using 10-kDa Amicon spin columns and dialyzed against sterile PBS using a 10-kDa cutoff membrane.

Protein concentration was determined using a Pierce BCA kit, and all protein was diluted such that a final concentration of $1 \mu \mathrm{g} / \mu \mathrm{L}$ in sterile PBS was achieved. Sterility of the 4Ig solution was confirmed by adding a small amount of purified 4 Ig to a plate containing DMEM without antibiotics, incubating at $37^{\circ} \mathrm{C}$, and monitoring for bacterial growth. Following dilution to $1 \mu \mathrm{g} / \mu \mathrm{L}$, the solution was aliquoted (20 $\mu \mathrm{L})$ and stored at $-80^{\circ} \mathrm{C}$ until immediately before use.

cAMP experiments. $\mathrm{Y} 79$ human retinoblastoma cells (ATCC) were seeded $4 \times 10^{6}$ in $10 \mathrm{~mL}$ RPMI medium containing $10 \% \mathrm{FBS}$ in $10-\mathrm{cm}$ plates and incubated at $37^{\circ} \mathrm{C}$. $0.5 \mathrm{mM} 8 \mathrm{Br}$-cAMP (Tocris) or $0.5 \mathrm{mM}$ $8 \mathrm{Br}$-cGMP (Tocris) was added to media and incubated for 48 hours. Concentrations were chosen based on commonly used concentrations used in cell culture assays (84). Total cell lysates were generated using RIPA buffer. Protein concentration was determined using a Pierce BCA kit. Western blots were done using neogenin (C20; Santa Cruz Biotechnology Inc.) and GAPDH (8245; Abcam) and imaged using the Odyssey system (LI-COR). Neogenin levels were normalized to the loading control, background was subtracted, and quantification was done on the raw data files using ImageStudio (LI-COR) software per the manufacturer's instructions.

Dissociated rod P3-P7 photoreceptors from Nrl-EGFP mice were prepared and plated as described previously (85). 100,000 cells per well were plated either in a 12-well plate containing poly-L-lysinecoated coverslips or a 96-well plate with a glass bottom. After settling for 2 hours, cells were incubated with or without $1 \mathrm{mM} 8 \mathrm{Br}$-cAMP for 24 or 72 hours. Concentrations of $8 \mathrm{Br}$-cAMP used were based on guidance from the literature (86). Cells were fixed in 4\% PFA for 15 minutes. Antibodies used were as follows: neogenin (H175; Santa Cruz Biotechnology Inc.) and cleaved caspase-3 (9664/ 9661; Abcam). For caspase-3 quantification, cell counts were performed on three $20 \times$ images per well and averaged. Each $n$ value represents a separate retina dissociation.

Extracellular spiking from RGCs. $\mathrm{C} 3 \mathrm{H} / \mathrm{HeJ}$ (Pde6b ${ }^{\text {rd1 }}$ ) mice were treated with intravitreal injections of 4Ig peptide on P8 and P13 and were subsequently used for recording on P29-P35. Only 1 or 2 retinas could be analyzed per day; however, all of the time points examined correspond to ages when robust light responses were absent in untreated Rd1 mice. Before recording, mice were dark adapted for approximately 30-60 minutes before being briefly anesthetized and decapitated. The retina was isolated under infrared light, with all vit- 
reous removed. The retina was then flat mounted on a piece of filter paper with a precut window, through which visual stimuli were presented to the photoreceptors. The mounted retina was perfused with warmed Ringer's solution $\left(35^{\circ} \mathrm{C}-37^{\circ} \mathrm{C}\right)$ containing $110 \mathrm{mM} \mathrm{NaCl}, 2.5$ $\mathrm{mM} \mathrm{KCl}, 1 \mathrm{mM} \mathrm{CaCl}_{2}, 1.6 \mathrm{mM} \mathrm{MgCl}_{2}, 10 \mathrm{mM}$ dextrose, and $22 \mathrm{mM}$ $\mathrm{NaHCO}_{3}$ that was bubbled with carbogen $\left(95 \% \mathrm{O}_{2}: 5 \% \mathrm{CO}_{2}\right)$. CNQX and DL-AP4 were purchased from Tocris Bioscience. Spike recordings were made using the loose cell-attached patch-clamp technique with 5- to 10-M $\Omega$ electrodes containing Ringer's solution.

Data were acquired using a MultiClamp 700B Amplifier (Molecular Devices). Analog signals were low-pass filtered at $2 \mathrm{kHz}$ and sampled at $10 \mathrm{kHz}$ with the Digidata $1440 \mathrm{~A}$ analog-to-digital board (Molecular Devices). Visual stimuli were produced via a blue LED projector (Acer) projected from below the preparation and were focused onto the outer segments of the photoreceptors with the help of the substage condenser. The stimuli were always 2-second bright spots $\left(9 \mathrm{~mW} / \mathrm{cm}^{2}\right)$ on a black background presented every 10 seconds. The responses were analyzed with custom software in MATLAB (MathWorks). In experiments studying increasing spot sizes, spatial selectivity index was calculated as $\left(R_{o p t}-R 1000 / R_{o p t}+R 1000\right)$, where $R o p t$ is the amplitude of the optimal spot $(200 / 400 \mu \mathrm{m})$ and $R 1000$ is the response to the $1000-\mu \mathrm{m}$ spot. Direction selectivity index was measured as $(\Sigma v i / \Sigma r i)$, where $v i$ are vectors pointing in the direction of the stimulus and having length ri, equal to the number of spikes recorded during that stimulus. Population data are expressed as mean \pm SEM. Student's $t$ test was used to compare values under different conditions, and the differences were considered significant when $P$ was less than 0.05 .

Electroretinogram recordings. Rd10 mice were treated with intravitreal injections of $2 \mu \mathrm{L}$ of either PBS or $4 \operatorname{Ig}(1 \mu \mathrm{g} / \mu \mathrm{L})$ on P20, and ERG recordings were performed on P30. ERG light stimulation and recordings were done using a Diagnosys Espion E3 rodent ERG device with a ColorDome Ganzfeld stimulator and Espion V6 software. All recordings were done in the dark with red light for illumination. Before recordings, mice were dark adapted overnight. The following day, mice were anesthetized using Avertin $(250 \mathrm{mg} / \mathrm{kg})$. Mydriatic eye drops were placed on the eyes so as to dilate the pupil. Body temperature was maintained at $38^{\circ} \mathrm{C}$ via a heated platform designed for mouse ERG recordings (Diagnosys). The cornea was kept moist with a thin layer of methylcellulose solution. Simultaneous bilateral recordings were done using gold loop electrodes placed on the cornea of each eye. A subdermal platinum reference electrode was placed between the eyes, and a ground platinum electrode was placed in the tail.

Light stimulation consisted of brief pulses of white light (6500K). Scotopic recordings were done first on the dark-adapted mouse. Five to 10 recordings per stimulus intensity were averaged, and the a- and b wave amplitudes were determined by the software. The following stimuli conditions (flash intensities) were used: $0.00025 \mathrm{~cd} / \mathrm{s} / \mathrm{m}^{2}$, $0.0025 \mathrm{~cd} / \mathrm{s} / \mathrm{m}^{2}, 0.025 \mathrm{~cd} / \mathrm{s} / \mathrm{m}^{2}, 0.25 \mathrm{~cd} / \mathrm{s} / \mathrm{m}^{2}, 2.5 \mathrm{~cd} / \mathrm{s} / \mathrm{m}^{2}, 5 \mathrm{~cd} / \mathrm{s} / \mathrm{m}^{2}$, and $10 \mathrm{~cd} / \mathrm{s} / \mathrm{m}^{2}$. Mice were then light adapted with $30 \mathrm{~cd} / \mathrm{s} / \mathrm{m}^{2}$ background illumination for 600 seconds. Photopic tests were done in the presence of $30 \mathrm{~cd} / \mathrm{s} / \mathrm{m}^{2}$ background illumination. Thirty recordings per flash intensity were averaged, and the amplitude of the $a-$ and $b$ waves was determined by the software. The following stimulus intensities were used: $0.15 \mathrm{~cd} / \mathrm{s} / \mathrm{m}^{2}, 1.25 \mathrm{~cd} / \mathrm{s} / \mathrm{m}^{2}, 5 \mathrm{~cd} / \mathrm{s} / \mathrm{m}^{2}, 10 \mathrm{~cd} / \mathrm{s} / \mathrm{m}^{2}, 25$ $\mathrm{cd} / \mathrm{s} / \mathrm{m}^{2}, 50 \mathrm{~cd} / \mathrm{s} / \mathrm{m}^{2}$, and $75 \mathrm{~cd} / \mathrm{s} / \mathrm{m}^{2}$. Data are presented as mean \pm SEM using GraphPad Prism software.
Optomotry testing. Rd10 or Rho ${ }^{\mathrm{P} 23 \mathrm{H} / \mathrm{P} 23 \mathrm{H}}$ mice were given intravitreal injections of either PBS or $4 \operatorname{Ig}(1 \mu \mathrm{g} / \mu \mathrm{L})$ on P2O or P10, and testing was done on P28 or P24, respectively, under normal lighting conditions. The tester was blinded to the treatment conditions and the spatial frequencies being tested during the procedure. Quantification of visual acuity was performed as described previously $(55,56)$. Custom software (OptoMotry VR 1.7.7) from CerebralMechanics running on an Apple computer projected a vertical sine wave grating on the monitors so as to create a virtual cylinder in the visual field of the mouse. A Zeiss video camera imaging the mouse from above projected to the associated Apple computer software; a bullseye was manually clamped via the software to the mouse's head so as to continuously center the virtual cylinder. The vertical sine wave gratings were then rotated around the mouse at 12 degrees/second using the randomized protocol design and the simple staircase psychophysical method within the software.

Statistics. Quantifications were done with the experimenter blinded to the treatment conditions. Statistical analysis was performed using GraphPad Prism software, and data are shown as mean \pm SEM. Results were considered significant if $P$ was less than 0.05. Significance of differences between 2 groups was determined using 2-tailed Student's $t$ test. For more than 2 groups, 1- or 2-way ANOVA followed by Šidák's multiple-comparisons test or Bonferroni's test was used as indicated in the figure legends.

Study approval. Immunocytochemical analysis was performed with the approval of the Cleveland Clinic Institutional Review Board (IRB 14-057) on eyes obtained through the Foundation Fighting Blindness (FFB) Eye Donor Program (see supplemental methods). Written informed consent was received from donors. The research adhered to the tenets of the Declaration of Helsinki. All animal studies were approved by the Animal Care Committee of the University Health Network, Toronto.

\section{Author contributions}

JC performed in vivo studies, data analysis, and biochemical experiments and wrote the manuscript. DC performed cAMP/PKA experiments. APS performed initial 4Ig experiments. GA designed experiments in RGCs. PM provided constructs. VLB performed human sample experiments. SS performed experiments in RGCs. $\mathrm{HH}$ performed in situ hybridizations. RB helped design experiments. PPM designed experiments and wrote the manuscript.

\section{Acknowledgments}

We thank Don and Nita Reed as well as the Krembil family for their constant support and enthusiasm for vision research. This work was supported by the Krembil Foundation (PPM, RB, GA), Fighting Blindness Canada (PPM), Brain Canada (PPM, RB), the NIH (EYO27750 to VLB), a National Eye Institute P30 Core Grant (P3OEY025585 to the Cleveland Clinic Foundation), and an unrestricted grant from Research to Prevent Blindness to the Cleveland Clinic Foundation. JC received support from the Vision Science Research Program of the University of Toronto. Human donor eyes were obtained through the FFB Eye Donor Program.

Address correspondence to: Philippe P. Monnier, Krembil Research Institute, 60 Leonard Avenue, Krembil Discovery Tower 8-428, Toronto, Ontario, M5T 2O8, Canada. Phone: 416.603.5295; Email:pmonnier@uhnres.utoronto.ca. 
1. Wright AF, Chakarova CF, Abd El-Aziz MM, Bhattacharya SS. Photoreceptor degeneration: genetic and mechanistic dissection of a complex trait. Nat Rev Genet. 2010;11(4):273-284.

2. Anasagasti A, Irigoyen C, Barandika O, López de Munain A, Ruiz-Ederra J. Current mutation discovery approaches in retinitis pigmentosa. Vision Res. 2012;75:117-129.

3. Daiger SP, Sullivan LS, Bowne SJ. Genes and mutations causing retinitis pigmentosa. Clin Genet. 2013;84(2):132-141.

4. Wen Y, Klein M, Hood DC, Birch DG. Relationships among multifocal electroretinogram amplitude, visual field sensitivity, and SD-OCT receptor layer thicknesses in patients with retinitis pigmentosa. Invest Ophthalmol Vis Sci. 2012;53(2):833-840.

5. Veleri S, Lazar CH, Chang B, Sieving PA, Banin E, Swaroop A. Biology and therapy of inherited retinal degenerative disease: insights from mouse models. Dis Model Mech. 2015;8(2):109-129.

6. Astakhova LA, Samoiliuk EV, Govardovskii VI, Firsov ML. cAMP controls rod photoreceptor sensitivity via multiple targets in the phototransduction cascade. J Gen Physiol. 2012;140(4):421-433.

7. Stryer L. Cyclic GMP cascade of vision. Annu Rev Neurosci. 1986;9:87-119.

8. Sancho-Pelluz J, et al. Photoreceptor cell death mechanisms in inherited retinal degeneration. Mol Neurobiol. 2008;38(3):253-269.

9. Cohen AI, Blazynski C. Dopamine and its agonists reduce a light-sensitive pool of cyclic AMP in mouse photoreceptors. Vis Neurosci. 1990;4(1):43-52.

10. Cohen AI, Todd RD, Harmon S, O'Malley KL. Photoreceptors of mouse retinas possess D4 receptors coupled to adenylate cyclase. Proc Natl Acad Sci U S A. 1992;89(24):12093-12097.

11. Nir I, et al. Dysfunctional light-evoked regulation of cAMP in photoreceptors and abnormal retinal adaptation in mice lacking dopamine $\mathrm{D} 4$ receptors. J Neurosci. 2002;22(6):2063-2073.

12. Stenkamp DL, Iuvone PM, Adler R. Photomechanical movements of cultured embryonic photoreceptors: regulation by exogenous neuromodulators and by a regulable source of endogenous dopamine. J Neurosci. 1994;14(5 pt 2):3083-3096.

13. Sahaboglu A, et al. Retinitis pigmentosa: rapid neurodegeneration is governed by slow cell death mechanisms. Cell Death Dis. 2013;4:e488.

14. Traverso V, Bush RA, Sieving PA, Deretic D Retinal cAMP levels during the progression of retinal degeneration in rhodopsin $\mathrm{P} 23 \mathrm{H}$ and S334ter transgenic rats. Invest Ophthalmol Vis Sci. 2002;43(5):1655-1661.

15. Weiss ER, et al. Altered cAMP levels in retinas from transgenic mice expressing a rhodopsin mutant. Biochem Biophys Res Commun. 1995;216(3):755-761.

16. Farber DB, Lolley RN. Influence of visual cell maturation or degeneration on cyclic AMP content of retinal neurons. J Neurochem. 1977;29(1):167-170.

17. Nakao T, Tsujikawa M, Notomi S, Ikeda Y, Nishida K. The role of mislocalized phototransduction in photoreceptor cell death of retinitis pigmentosa. PLOS ONE. 2012;7(4):e32472.

18. Paquet-Durand F, Hauck SM, van Veen T, Ueffing
M, Ekström P. PKG activity causes photoreceptor cell death in two retinitis pigmentosa models. J Neurochem. 2009;108(3):796-810.

19. Bouchard JF, et al. Protein kinase A activation promotes plasma membrane insertion of DCC from an intracellular pool: a novel mechanism regulating commissural axon extension. JNeurosci. 2004;24(12):3040-3050.

20. Schwab JM, et al. Central nervous system injury-induced repulsive guidance molecule expression in the adult human brain. Arch Neurol. 2005;62(10):1561-1568

21. Mehlen P, Bredesen DE. Dependence receptors: from basic research to drug development. $S c i$ Signal. 2011;4(157):mr2.

22. Tassew NG, et al. Modifying lipid rafts promotes regeneration and functional recovery. Cell Rep. 2014;8(4):1146-1159.

23. Di Polo A, Farber DB. Rod photoreceptor-specific gene expression in human retinoblastoma cells. Proc Natl Acad Sci U S A. 1995;92(9):4016-4020.

24. Arango-Gonzalez B, et al. Identification of a common non-apoptotic cell death mechanism in hereditary retinal degeneration. PLOS ONE. 2014;9(11):e112142.

25. Shabanzadeh AP, et al. Uncoupling Neogenin association with lipid rafts promotes neuronal survival and functional recovery after stroke. Cell Death Dis. 2015;6:e1744.

26. Han J, Dinculescu A, Dai X, Du W, Smith WC, Pang J. Review: the history and role of naturally occurring mouse models with Pde6b mutations. Mol Vis. 2013;19:2579-2589.

27. Pittler SJ, Baehr W. Identification of a nonsense mutation in the rod photoreceptor cGMP phosphodiesterase beta-subunit gene of the rd mouse. Proc Natl Acad Sci U S A. 1991;88(19):8322-8326.

28. Portera-Cailliau C, Sung CH, Nathans J, Adler R. Apoptotic photoreceptor cell death in mouse models of retinitis pigmentosa. Proc Natl Acad Sci U S A. 1994;91(3):974-978.

29. Kranz K, Paquet-Durand F, Weiler R, Janssen-Bienhold U, Dedek K. Testing for a gap junction-mediated bystander effect in retinitis pigmentosa: secondary cone death is not altered by deletion of connexin 36 from cones. PLOS ONE. 2013;8(2):e57163.

30. Sakami S, et al. Probing mechanisms of photoreceptor degeneration in a new mouse model of the common form of autosomal dominant retinitis pigmentosa due to $\mathrm{P} 23 \mathrm{H}$ opsin mutations. J Biol Chem. 2011;286(12):10551-10567.

31. Barhoum R, et al. Functional and structural modifications during retinal degeneration in the $\mathrm{rd} 10$ mouse. Neuroscience. 2008;155(3):698-713.

32. Gargini C, Terzibasi E, Mazzoni F, Strettoi E. Retinal organization in the retinal degeneration 10 (rd10) mutant mouse: a morphological and ERG study. JComp Neurol. 2007;500(2):222-238.

33. Sahaboglu A, et al. Retinitis pigmentosa: rapid neurodegeneration is governed by slow cell death mechanisms. Cell Death Dis. 2013;4:e488.

34. Hamel C. Retinitis pigmentosa. Orphanet J Rare Dis. 2006;1:40.

35. Schnichels S, Heiduschka P, Julien S. RGMA and neogenin protein expression are influenced by lens injury following optic nerve crush in the rat retina. Graefes Arch Clin Exp Ophthalmol.
2012;250(1):39-50.

36. Koeberle PD, Tura A, Tassew NG, Schlichter LC, Monnier PP. The repulsive guidance molecule, RGMa, promotes retinal ganglion cell survival in vitro and in vivo. Neuroscience. 2010;169(1):495-504.

37. Matsuda T, Cepko CL. Electroporation and RNA interference in the rodent retina in vivo and in vitro. Proc Natl Acad Sci U S A. 2004;101(1):16-22.

38. Matsunaga E, et al. RGM and its receptor neogenin regulate neuronal survival. Nat Cell Biol. 2004;6(8):749-755

39. Friedrich S, Cheng YL, Saville B. Drug distribution in the vitreous humor of the human eye: the effects of intravitreal injection position and volume. Curr Eye Res. 1997;16(7):663-669.

40. Akiyode O, Major J, Ojo A. Aflibercept: a review of its use in the management of diabetic eye complications. JPharm Pract. 2017;30(5):534-540.

41. Mitra RN, Zheng M, Weiss ER, Han Z. Genomic form of rhodopsin DNA nanoparticles rescued autosomal dominant retinitis pigmentosa in the P23H knock-in mouse model. Biomaterials. 2018;157:26-39.

42. Liu H, et al. Photoreceptor cells influence retinal vascular degeneration in mouse models of retinal degeneration and diabetes. Invest Ophthalmol Vis Sci. 2016;57(10):4272-4281.

43. Nakamura PA, et al. Small molecule Photoregulin 3 prevents retinal degeneration in the RhoP $23^{H}$ mouse model of retinitis pigmentosa. Elife. 2017;6:e30577.

44. Beltran WA. On the role of CNTF as a potential therapy for retinal degeneration: Dr. Jekyll or Mr. Hyde? Adv Exp Med Biol. 2008;613:45-51.

45. LaVail MM, et al. Protection of mouse photoreceptors by survival factors in retinal degenerations. Invest Ophthalmol Vis Sci. 1998;39(3):592-602.

46. Schlichtenbrede FC, et al. Intraocular gene delivery of ciliary neurotrophic factor results in significant loss of retinal function in normal mice and in the Prph2Rd2/Rd2 model of retinal degeneration. Gene Ther. 2003;10(6):523-527.

47. Liang $\mathrm{FQ}$, et al. Long-term protection of retinal structure but not function using RAAV.CNTF in animal models of retinitis pigmentosa. Mol Ther. 2001;4(5):461-472.

48. Rhee KD, Nusinowitz S, Chao K, Yu F, Bok D, Yang XJ. CNTF-mediated protection of photoreceptors requires initial activation of the cytokine receptor gp130 in Müller glial cells. Proc Natl Acad Sci U S A. 2013;110(47):E4520-E4529.

49. Stasheff SF. Emergence of sustained spontaneous hyperactivity and temporary preservation of OFF responses in ganglion cells of the retinal degeneration (rd1) mouse. J Neurophysiol. 2008;99(3):1408-1421.

50. Stasheff SF, Shankar M, Andrews MP. Developmental time course distinguishes changes in spontaneous and light-evoked retinal ganglion cell activity in rd1 and rd10 mice. J Neurophysiol. 2011;105(6):3002-3009.

51. Farrow K, et al. Ambient illumination toggles a neuronal circuit switch in the retina and visual perception at cone threshold. Neuron. 2013;78(2):325-338.

52. Hoggarth A, et al. Specific wiring of distinct amacrine cells in the directionally selective retinal 
circuit permits independent coding of direction and size. Neuron. 2015;86(1):276-291.

53. Chang B, et al. Two mouse retinal degenerations caused by missense mutations in the beta-subunit of rod cGMP phosphodiesterase gene. Vision Res. 2007;47(5):624-633.

54 . Wang K, et al. Retinal structure and function preservation by polysaccharides of wolfberry in a mouse model of retinal degeneration. Sci Rep. 2014;4:7601.

55. Douglas RM, Alam NM, Silver BD, McGill TJ, Tschetter WW, Prusky GT. Independent visual threshold measurements in the two eyes of freely moving rats and mice using a virtual-reality optokinetic system. Vis Neurosci. 2005;22(5):677-684.

56. Prusky GT, Alam NM, Beekman S, Douglas RM. Rapid quantification of adult and developing mouse spatial vision using a virtual optomotor system. Invest Ophthalmol Vis Sci. 2004;45(12):4611-4616.

57. Sanyal S, Fletcher R, Liu YP, Aguirre G, Chader G. Cyclic nucleotide content and phosphodiesterase activity in the rds mouse (020/A) retina. Exp Eye Res. 1984;38(3):247-256.

58. Nir I, Haque R, Iuvone PM. Regulation of cAMP by light and dopamine receptors is dysfunctional in photoreceptors of dystrophic retinal degeneration slow(rds) mice. Exp Eye Res. 2001;73(2):265-272.

59. Chen Y, et al. Systems pharmacology identifies drug targets for Stargardt diseaseassociated retinal degeneration. JClin Invest. 2013;123(12):5119-5134.

60. Wen R, Cheng T, Li Y, Cao W, Steinberg RH. Alpha 2-adrenergic agonists induce basic fibroblast growth factor expression in photoreceptors in vivo and ameliorate light damage. J Neurosci. 1996;16(19):5986-5992.

61. Bush RA, Sugawara T, Iuvone PM, Sieving PA. Melatonin receptor blockers enhance photoreceptor survival and function in light damaged rat retina. In: Hollyfield JG, Anderson RE, LaVail MM, eds. Retinal Degenerative Diseases and Experimental Therapy. Boston, Massachusetts, USA: Springer; 1999:539-550.

62. Sancho-Pelluz J, et al. Photoreceptor cell death mechanisms in inherited retinal degeneration. Mol Neurobiol. 2008;38(3):253-269.

63. Insel PA, Zhang L, Murray F, Yokouchi H, Zam- bon AC. Cyclic AMP is both a pro-apoptotic and anti-apoptotic second messenger. Acta Physiol (Oxf). 2012;204(2):277-287.

64. Chen M, Schnermann J, Smart AM, Brosius FC, Killen PD, Briggs JP. Cyclic AMP selectively increases renin mRNA stability in cultured juxtaglomerular granular cells. J Biol Chem. 1993;268(32):24138-24144.

65. Hod Y, Hanson RW. Cyclic AMP stabilizes the mRNA for phosphoenolpyruvate carboxykinase (GTP) against degradation. J Biol Chem. 1988;263(16):7747-7752.

66. Rataj F, et al. The cAMP pathway regulates mRNA decay through phosphorylation of the RNA-binding protein TIS11b/BRF1. Mol Biol Cell. 2016;27(24):3841-3854.

67. Chang GQ, Hao Y, Wong F. Apoptosis: final common pathway of photoreceptor death in rd, rds, and rhodopsin mutant mice. Neuron. 1993;11(4):595-605.

68. Kim DH, Kim JA, Choi JS, Joo CK. Activation of caspase-3 during degeneration of the outer nuclear layer in the rd mouse retina. Ophthalmic Res. 2002;34(3):150-157.

69. Nickells RW, Zack DJ. Apoptosis in ocular disease: a molecular overview. Ophthalmic Genet. 1996;17(4):145-165.

70. Liu C, Li Y, Peng M, Laties AM, Wen R. Activation of caspase-3 in the retina of transgenic rats with the rhodopsin mutation s334ter during photoreceptor degeneration. J Neurosci. 1999;19(12):4778-4785.

71. Sanges D, Comitato A, Tammaro R, Marigo V. Apoptosis in retinal degeneration involves crosstalk between apoptosis-inducing factor (AIF) and caspase-12 and is blocked by calpain inhibitors. Proc Natl Acad Sci U S A. 2006;103(46):17366-17371.

72. Fujita $Y$, et al. Neogenin regulates neuronal survival through DAP kinase. Cell Death Differ. 2008;15(10):1593-1608.

73. Shohat $\mathrm{G}$, et al. The pro-apoptotic function of death-associated protein kinase is controlled by a unique inhibitory autophosphorylation-based mechanism. J Biol Chem. 2001;276(50):47460-47467.

74. Singh P, Ravanan P, Talwar P. Death associated protein kinase 1 (DAPK1): a regulator of apoptosis and autophagy. Front Mol Neurosci. 2016;9:46.
75. Gozuacik D, et al. DAP-kinase is a mediator of endoplasmic reticulum stress-induced caspase activation and autophagic cell death. Cell Death Differ. 2008;15(12):1875-1886.

76. Yang LP, Wu LM, Guo XJ, Tso MO. Activation of endoplasmic reticulum stress in degenerating photoreceptors of the rd1 mouse. Invest Ophthal mol Vis Sci. 2007;48(11):5191-5198.

77. Trenholm S, Awatramani GB. Origins of spontaneous activity in the degenerating retina. Front Cell Neurosci. 2015;9:277.

78. Trenholm S, et al. Intrinsic oscillatory activity arising within the electrically coupled AII amacrine-ON cone bipolar cell network is driven by voltage-gated $\mathrm{Na}+$ channels. J Physiol (Lond). 2012;590(10):2501-2517.

79. Toychiev AH, Ivanova E, Yee CW, Sagdullaev BT. Block of gap junctions eliminates aberrant activity and restores light responses during retinal degeneration. J Neurosci. 2013;33(35):13972-13977.

80. Jacobson SG, et al. Improvement and decline in vision with gene therapy in childhood blindness. N Engl J Med. 2015;372(20):1920-1926.

81. Chen B, Cepko CL. HDAC4 regulates neuronal survival in normal and diseased retinas. Science. 2009;323(5911):256-259.

82. Cayouette M, Gravel C. Adenovirus-mediated gene transfer of ciliary neurotrophic factor can prevent photoreceptor degeneration in the retinal degeneration (rd) mouse. Hum Gene Ther. 1997;8(4):423-430.

83. Birch DG, Bennett LD, Duncan JL, Weleber RG, Pennesi ME. Long-term follow-up of patients with retinitis pigmentosa receiving intraocular ciliary neurotrophic factor implants. Am JOphthalmol. 2016;170:10-14.

84. Sposini S, et al. Integration of GPCR signaling and sorting from very early endosomes via opposing APPL1 mechanisms. Cell Rep. 2017;21(10):2855-2867.

85. Smiley S, et al. Establishment of a cone photoreceptor transplantation platform based on a novel cone-GFP reporter mouse line. Sci Rep. 2016;6:22867.

86. Chyb S, Hevers W, Forte M, Wolfgang WJ, Selinger Z, Hardie RC. Modulation of the light response by cAMP in Drosophila photoreceptors. JNeurosci.1999;19(20):8799-8807. 